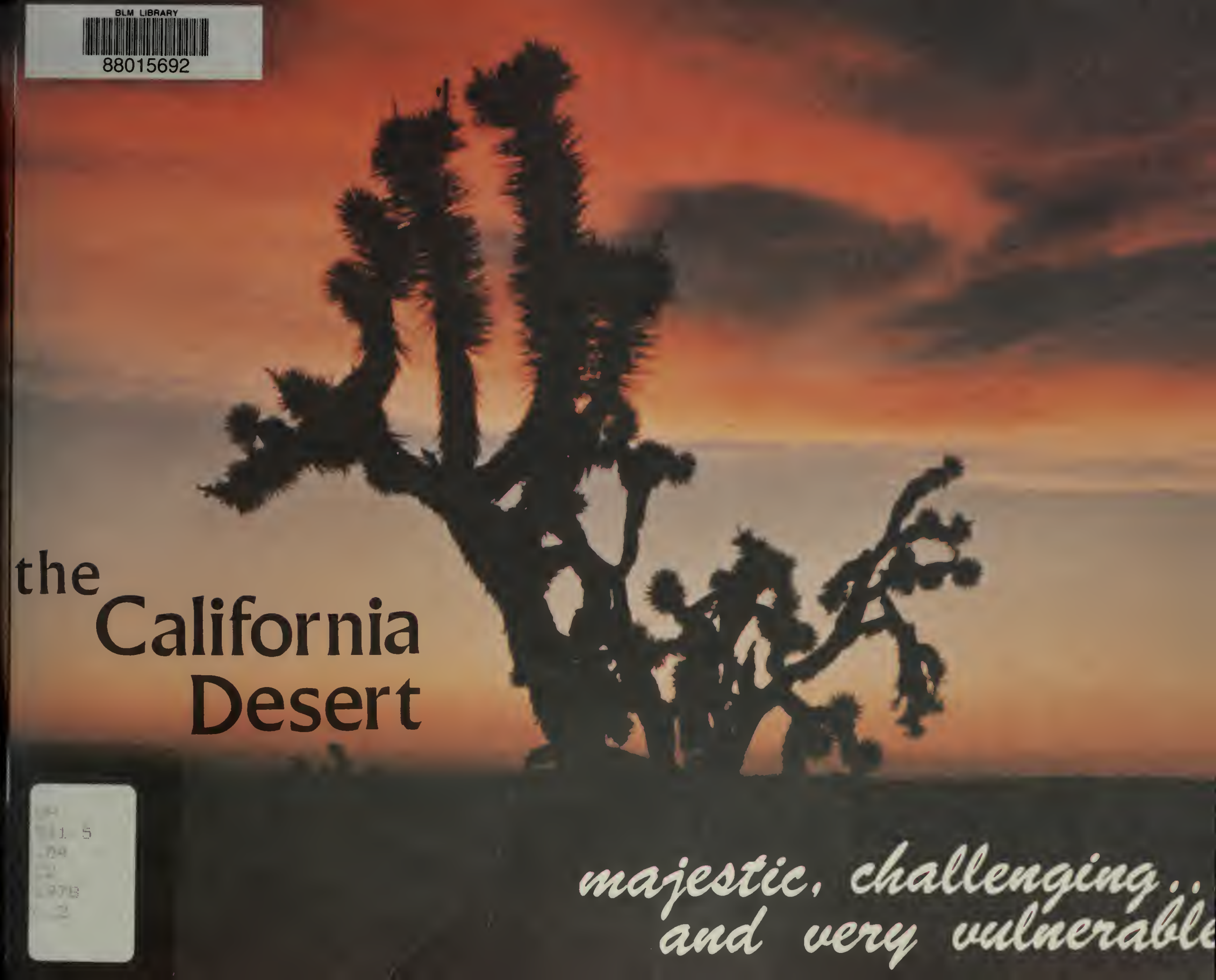




\section{This is the}

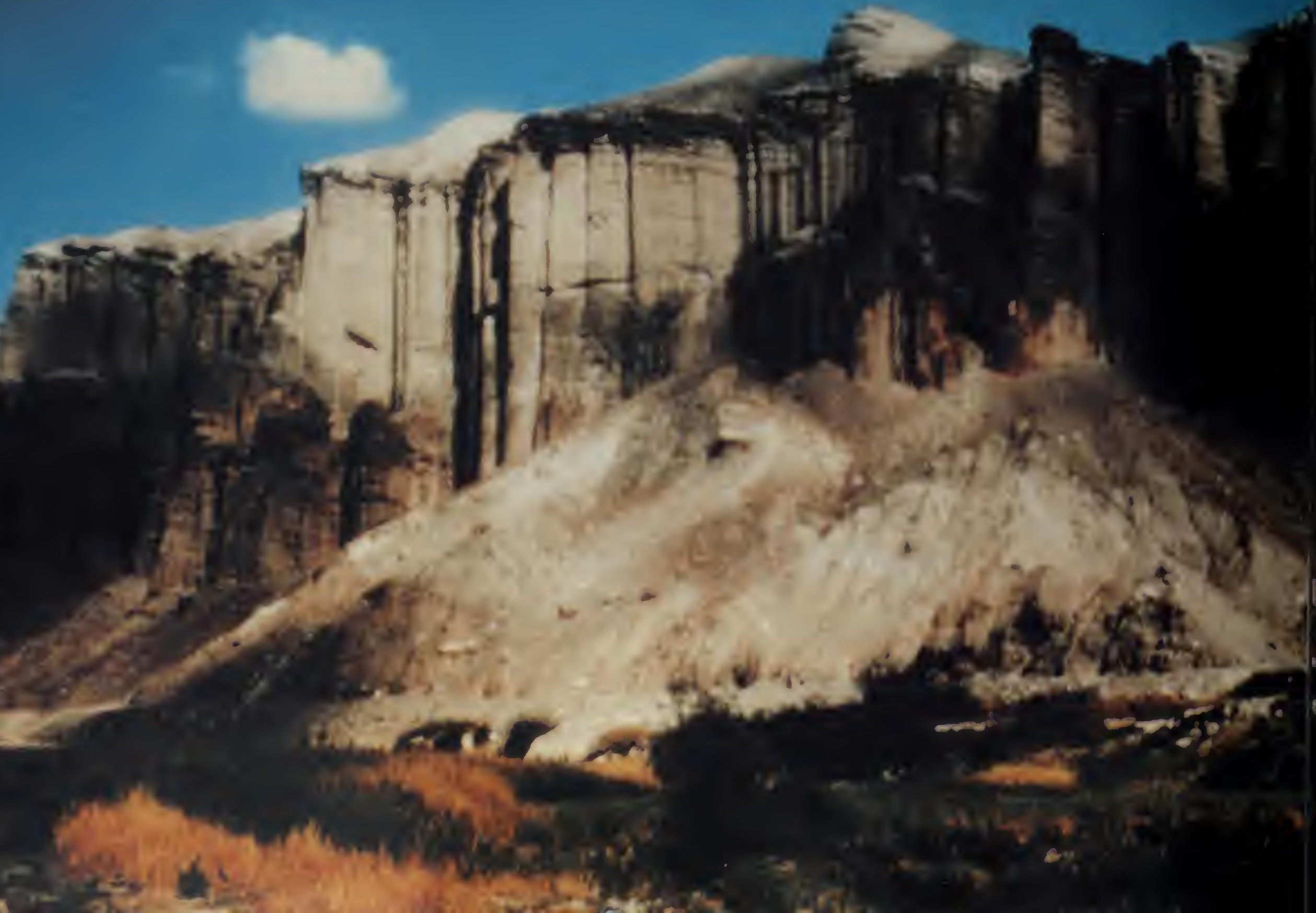




\section{alifornia \\ Desert...}

BLM LIbrary

D-583A, Bullding 50

Denver Federal Center

P. O. Box 25047

Denver, $C 0$ 80225-0047

a place of

grandeur,

beauty, and

myriad natural

resources ...

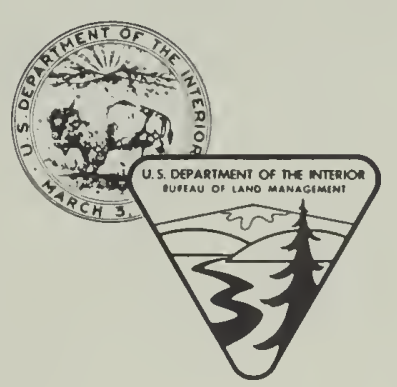

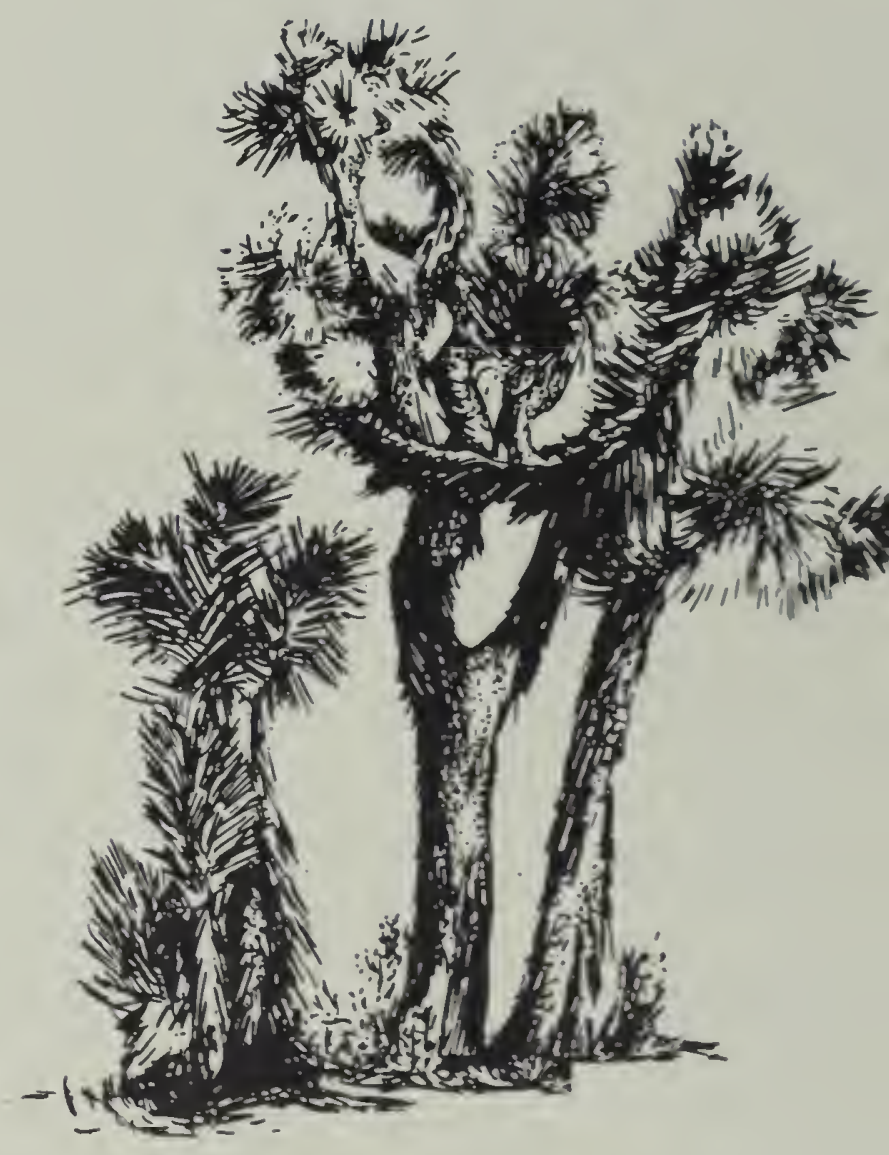




\section{and... So is this!}

a century of neglect and abuse is taking its toll on this splendid land!

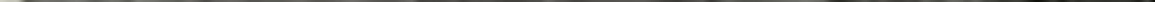




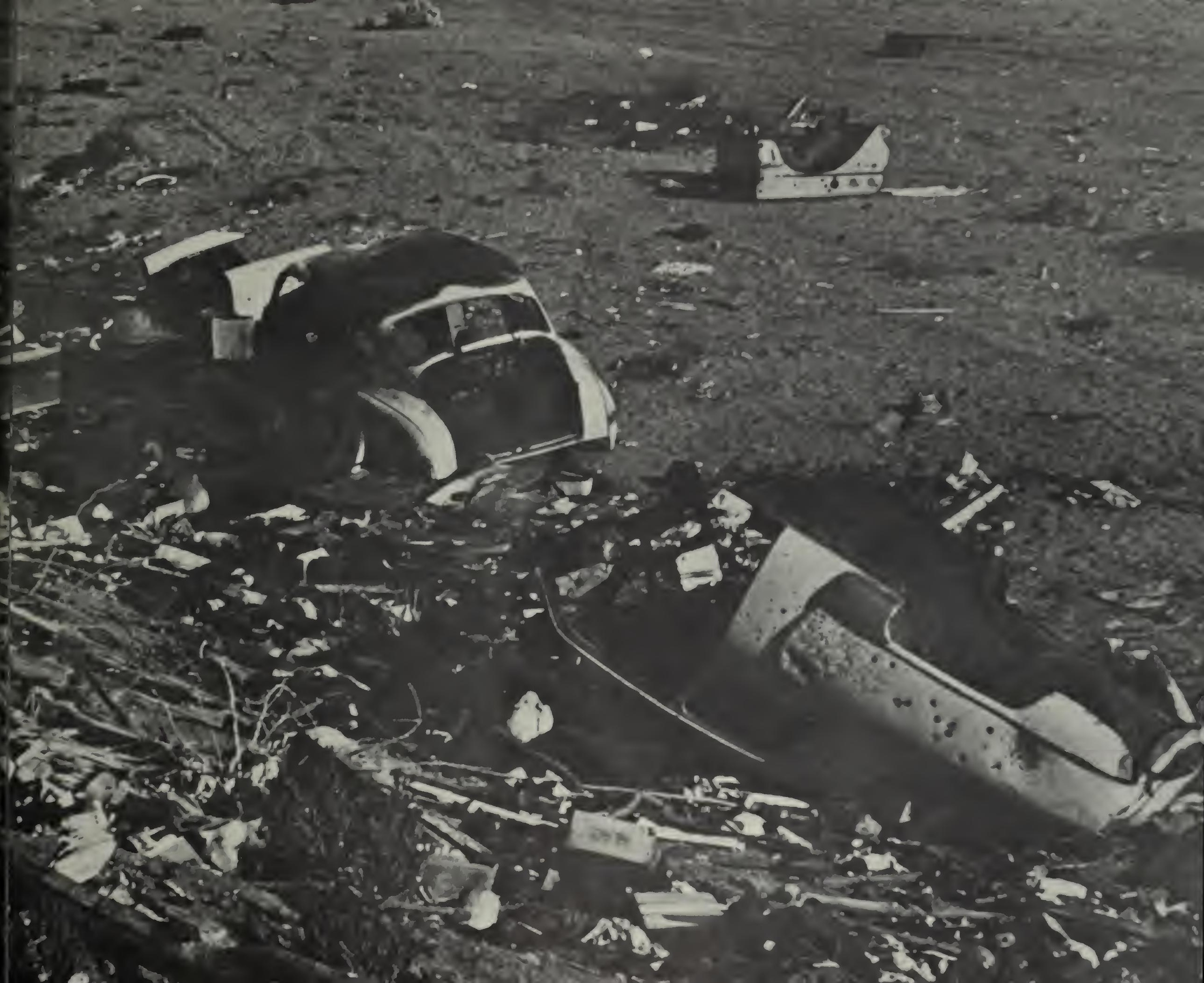




\section{the California Desert}

\section{no longer tranquil}

H land that America crossed to reach the rich mines, the valleys and towns west of the bordering mountains. But as the valleys were taken up, and the lucrative veins worked out, many turned eastward again to try farming or ranching, prospecting or mining. Then as the cities of Los Angeles and San Diego burgeoned and fused into one teeming megalopolis to the west, and other cities sprang up around the desert's perimeter, the uncontrolled spillover of humanity began causing havoc with the delicate balance of this relatively undisturbed land.

C Conficts, usually verbal but at times physical cropped up between groups with clashing interests. Dune-buggy buffs and jeepers collided with conservation groups, as well as each other. Bogus mining claims tied up lands which others wanted and deserved, while legitimate mining began spewing unsightly fans of tailings over previously unblemished landscapes. The interests of amateur collectors of artifacts clashed with those of historians and archaeologists, sheep grazers squabbled with cattlemen, naturalists and animal lovers became incensed at the ever increasing number of hunters.

The pressure was mounting fast!
Landscape artists and photographers complained about the 3,500 miles of power lines, 12,000 miles of pipelines and dozens of microwave repeater stations. Slightly more than a hundred settlements housed nearly half-a-million people. Odious layers of brown smog, once considered the exclusive province of the Los Angeles Basin, came seeping through mountain passes, withering farm produce and damaging precious forage.

$\mathbf{E}_{\mathrm{v}}$ forage crops, and other materials have been produced; despite the presence of remarkable historic, cultural, scientific and educational values; and in spite of the sometimes intangible social and recreational use by millions of people yearly; there are great voids in our knowledge of the California desert. Shamefully, said some, there had been no effort to consider the whole, to evaluate the future of the desert in terms of its total environment. Without such an evaluation, they warned, the several unchecked, single-purpose invasions into the desert constituted environmental brinkmanship of the most dangerous order.

The warning had been sounded... An overall plan was badly needed! 


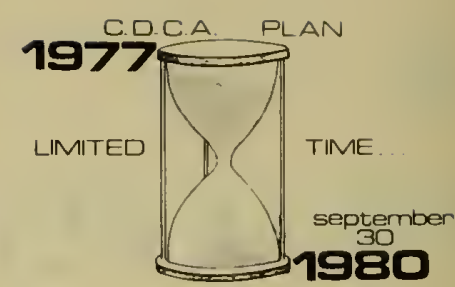

\section{A NEW MANAGEMENT}

\section{STRATEGY FOR THE}

\section{CALIFORNIA DESERT . .}

The planning effort taking place in the California desert today - a task unprecedented in scope and complexity - had its origins in the late sixties. By that time the impacts of recreationists had brought the Bureau of Land Management to a new reality. Abuse of highly sensitive resources was taking place at an alarming rate. The abuse was both deliberate and inadvertent. The age of passive management in the desert had to end. It was mandatory to halt and turn back a trend that would truly make a wasteland of this desert. A small-scale study of recreation impacts confirmed the most dire estimates. BLM began a modestly financed "Desert Program" to curb the most extreme abuses and to begin the long-range planning for all resources in the desert. A minimal Desert Plan Staff (DPS), made up of several disciplines, began the planning process on an area-by-area basis.

\section{Federal}

\section{Land}

\section{Policy and}

\section{Management}


The first targets for resource inventories were three planning units - Yuha, El Paso/Red Mountain and East Mojave Area - totalling four million acres. These units comprised one-fourth of the total acreage for which planning was required, $12 \frac{1}{2}$ million acres of BLM public domain and the remainder interspersed private holdings. At the rate that the work progressed it was estimated that at least 12 years would be needed to do the job.

Everyone realized that 12 years was too long. On the western flank of the study area lay a vast metropolis of 12 million people. Their appetite for things the desert could provide was insatiable and growing by geometric progression. They had already made a playground out of the desert. They needed more and more water, power lines, electric lines, petroleum pipelines, telephone lines, power sites, minerals. Within 12 years many irreversible commitments of resources would have to be made; the planning process had to be speeded up.

Congress responded late in 1976 with the Federal Land Policy and Management Act (FLPMA), which contained a new planning approach. It established the California Desert Conservation Area, totalling 25 million acres and constituting one-fourth of the state's total land surface. The planning area stretches 500 miles, from north of Death Valley National Monument to the Mexican Border. It is 200 miles wide, reaching from the Colorado River to fringes of the Los Angeles metropolitan area.

The new legislation authorized ten million dollars to conduct resource inventories and prepare a long-range plan for resource use. It called for maximum public involvement in the planning process. A 15-citizen Advisory Committee was appointed to serve as a key element in assuring public participation. Finally, the Act set a tighter deadline for completion of the Desert Plan. The California Desert Plan must be in the hands of the Secretary of the Interior by October 1, 1980.

\section{inta}

\section{FLPMA's}

\&

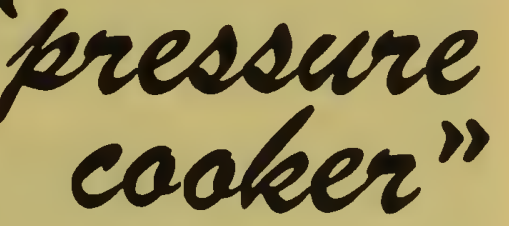

$A$ TREMENDOUS TASK

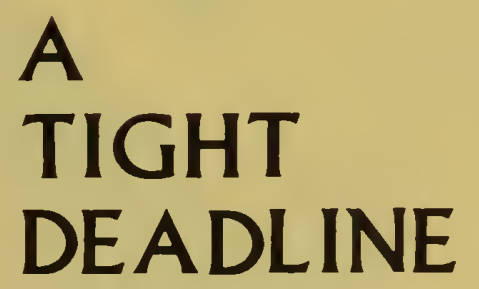




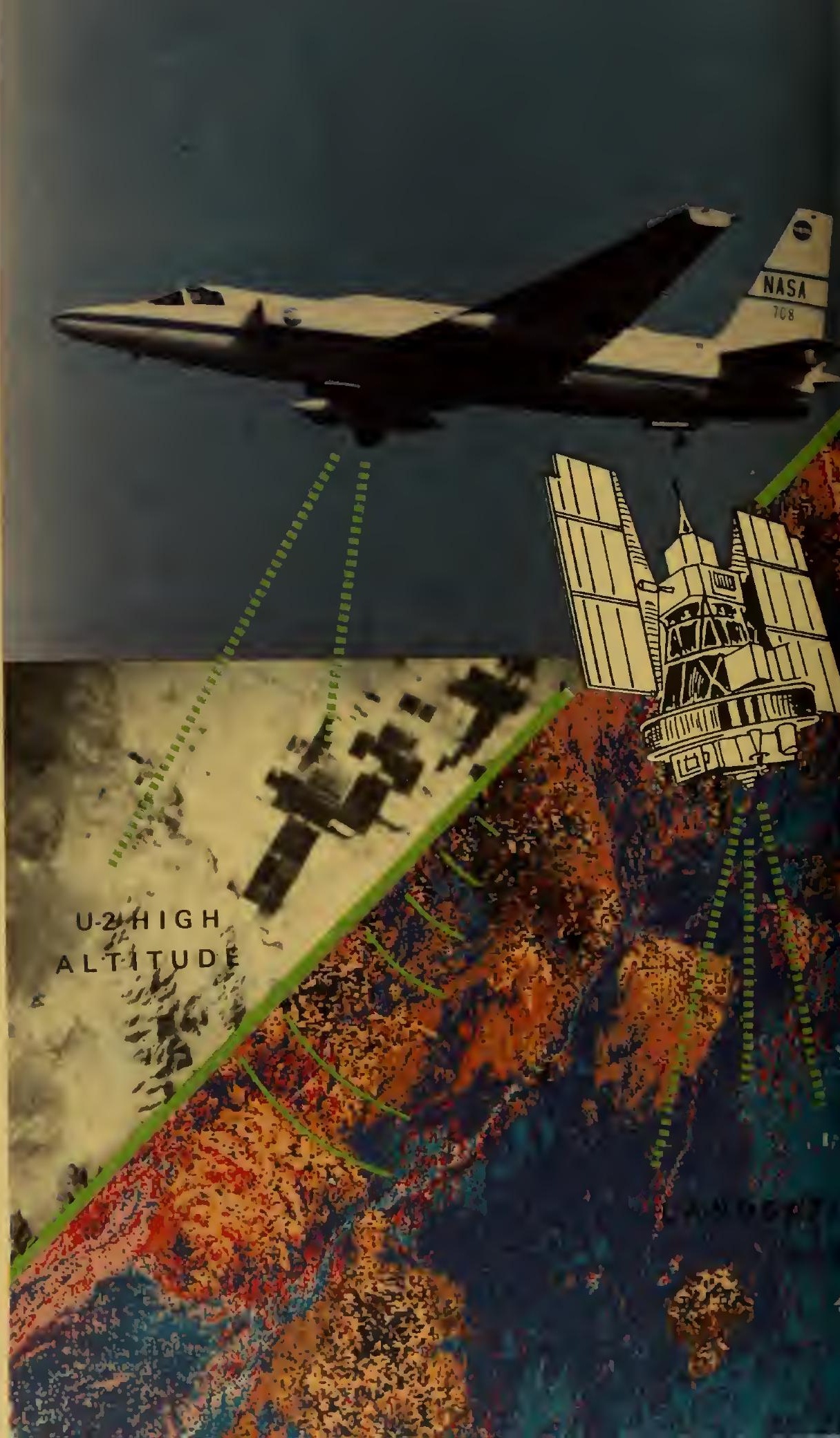


$\mathbf{R}$

ecorded knowledge about the California desert began with the journals of Spanish explorers more than two centuries ago. This "data base" has been slowly building since that time, fed by many people and organizations, each of whom had specialized requirements. In terms of modern needs, their records are fragmented, incomplete, and unrelated. But they were an essential beginning.

The first step for the Desert Plan Staff was to conduct an exhaustive search of all existing information it could find - any literature, maps and notes that pertained to the 25-million-acre conservation area. Significant input came from Federal agencies such as the Bureau of Mines, Geological Survey, Soil Conservation Service, from state and county agencies, and from museums and private collections. All of this data was banked into the DPS high-speed, high-capacity minicomputer for future use.

One glaring fact stood out. There was not nearly enough data, especially concerning natural and cultural resources. Before the Desert Plan Staff could make recommendations concerning the longrange use of these resources, it had to know a great deal more of which individual resources there were in the desert, where they occur, and their abundance.

The FLPMA deadline, (October 1, 1980), for completion of the plan required that the DPS change from the planning-unit approach to a system of desert-wide data collection. It also required more use of space age technology to view broad areas of the desert, rather than placing emphasis on field crew operations. This important new aid in planning is statistical and image data that is remotely sensed and recorded or transmitted from conventional aircraft, U-2 high-flight aircraft, and from NASA satellites. All of this data is computer stored and can be used to identify resources on the ground.

The identification process has varying demands. For example, recognition of plant species is more effective at altitudes of 500 to 1,000 feet. Geologic faults, surface-water drainage patterns, and other major land forms are more readily analyzed from altitudes of 50,000 feet and higher. Most of the photography for inventorying other resources is done between 20,000 and 30,000 feet. Also being utilized are color photos from NASA U-2's taken from approximately 60,000 feet and encompassing most of the California Desert Conservation Area.

\section{SPACE AGE TECHNIQUES}

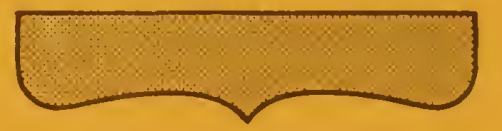


A

dditionally, remotely sensed data obtained from NASA's LandSat satellites is being used in preparing inventories of minerals, geology, soil types, vegetation, and wildlife habitat. When pieced together, approximately 10 LandSat images provide a continuous overview of the entire CDCA.

LandSat satellites are about 750 miles from the earth's surface, providing an unbroken panoramic view of the entire California Desert Conservation Area. By comparing the larger-scale U-2 photos with the smaller-scale satellite images, objects only partially discernible in the imagery are readily detected and interpreted.

On-the-spot ground checks, performed by field crews, further examine what certain objects appearing on the satellite images and larger-scale photos actually are. This practice permits interpretation of similar images in other areas not ground checked. Where discrepancies are noted between remotely sensed information and previously recorded data, this same "ground-truthing" technique is used to update and correct existing maps and other records.

"Mapping" certain resources in the CDCA by superimposing remotely sensed data on existing information is accomplished in two phases. The first results in a small-scale representation of the overall area under study. In the case of mineral resources, for example, this method necessarily produces relatively generalized data showing comparatively little detail. The primary purpose of the first phase is to select "probable" areas, or those of unusual interest, to which field crews (in the second phase) may be sent for intensive ground examination. Ground checks isolate pockets of "high-confidence" level data. A substantial amount of this "high-confidence" information may be extrapolated, or projected, over the entire study area for final research and analysis.

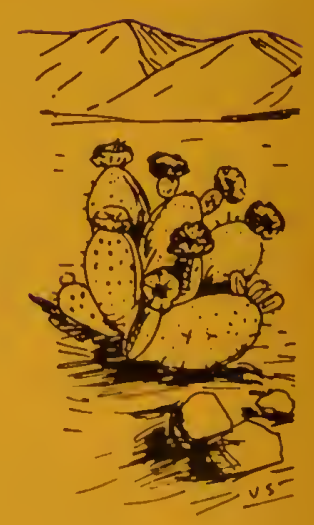




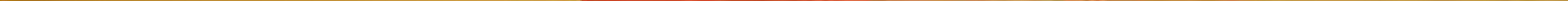




\section{Most of us take the DESERT for granted....}

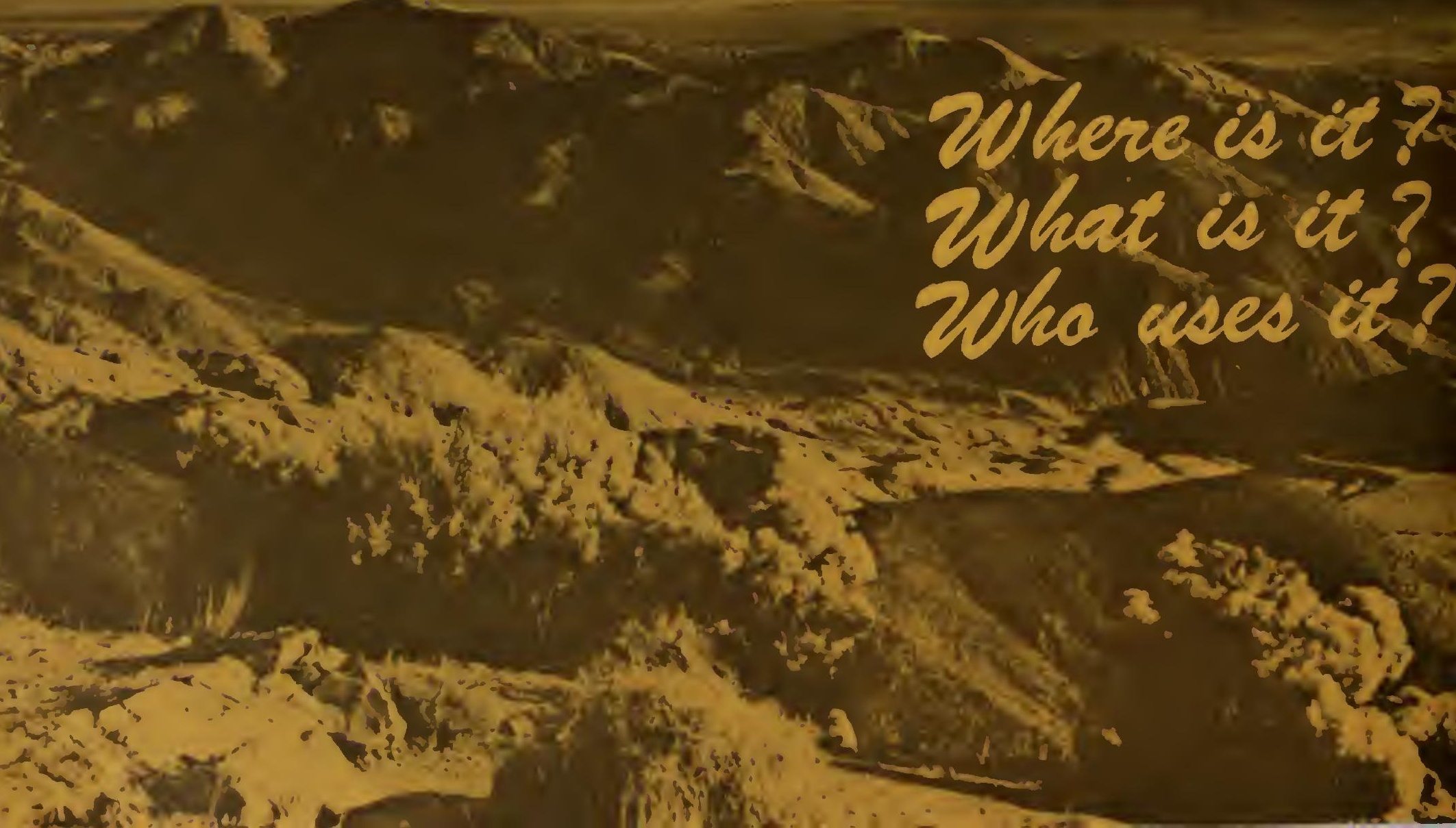





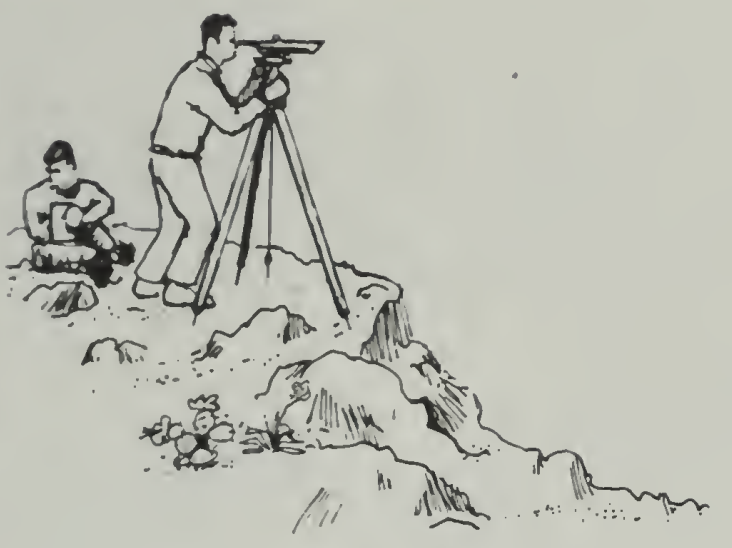

Since the early years of the nineteenth century, there have been increasing uses made of the lands comprising the California Desert Conservation Area. There were many years when this increased use could be attributed almost solely to mining interests. When the first train track was laid across the desert, vast acreages were granted to the railroads. Subsequently, the Federal government allocated significant sections of the desert for military reservations and national monuments.

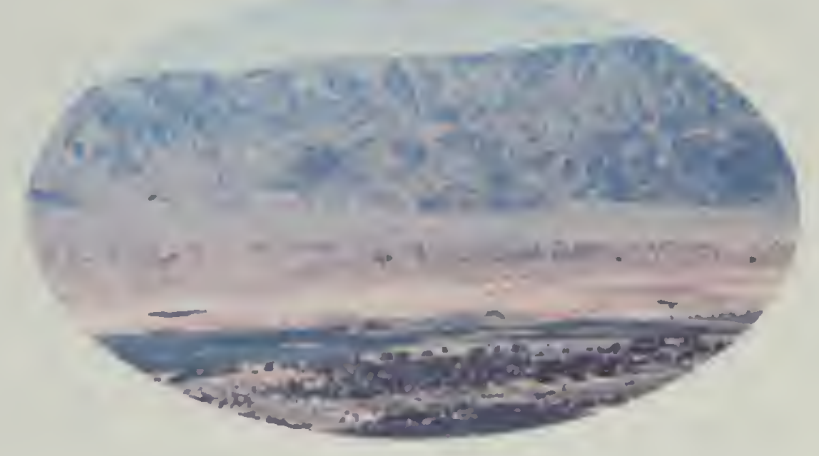

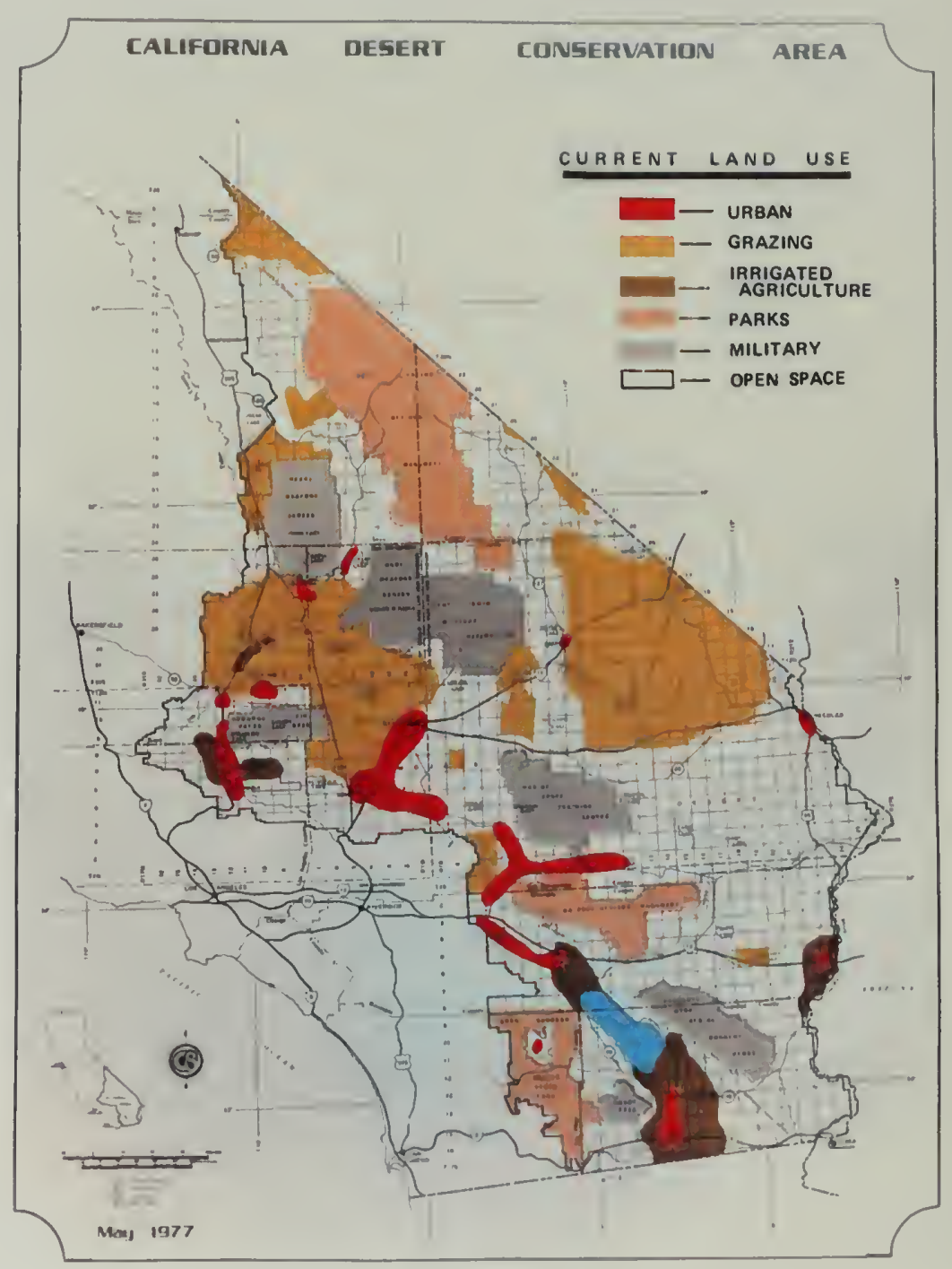


Agriculture and urbanization have accounted for a relatively small percentage of the total land use of the California desert, largely because of the lack of water. One exception has been the combined Imperial/Coachella Valley, fortunate to be supplied with Colorado River water. After the turn of the century, livestock grazing gradually became a factor on that 20 percent of desert lands which supported ample forage.

Several years later, as the need for energy from various sources expanded, major utility rights-of-way were established and eventually accounted for many thousands of desert acres. During the war years of the forties, a major portion of the central desert area was subjected to intensive use by military maneuvers.

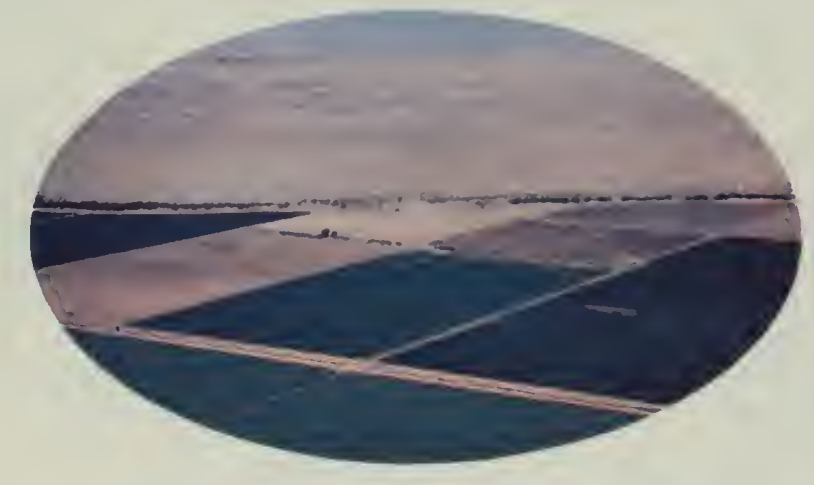

Then the recreationists discovered the desert. Thousands of campers, trailers, motorcycles, dune buggies, four-wheeldrive vehicles, and other recreation

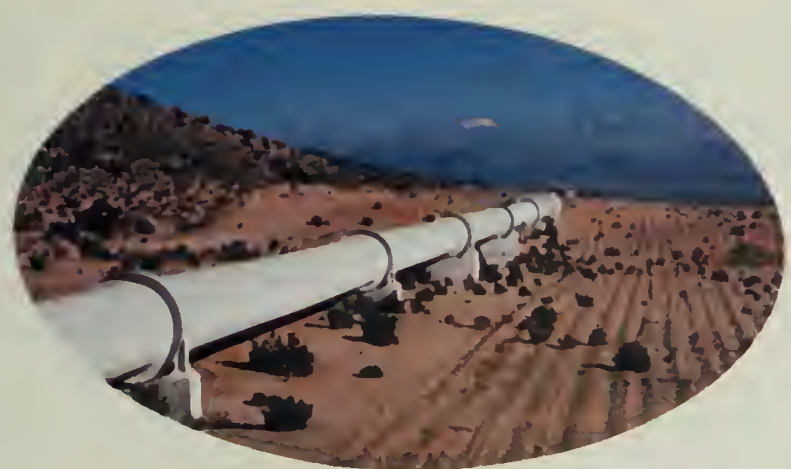
vehicles streamed into the desert on weekends from surrounding metropolitan areas.

Future land use will have to cope with many different needs which will be generated by population growth. Some of those needs may include solid-waste disposal, pollution prevention, airports, urban and industrial expansion, commercial uses, and public utilities, as well as the problems of resource use. 


\section{Energy}

Of all California desert resources in great need of analysis, geology is one of the most neglected. It is also one of the most complex. This stems partially from its three-dimensional nature - it deals not only with the surface of the earth, but to a depth of many miles beneath. Adding to the complexities is yet another dimension - time. The geology of the CDCA includes types of rocks ranging in age from Precambrian times, more than 600 million years ago, to rocks still being formed today.

LandSat satellite imagery and U-2 high-altitude photography programs are expected to benefit the G-E-M (Geology, Energy, Minerals) inventory. One LandSat imagery study will shed new information on fractures, faults, and fault systems in the earth's crust, and their relationship to mineralization. Also, knowledge about earthquake hazards might be enhanced.

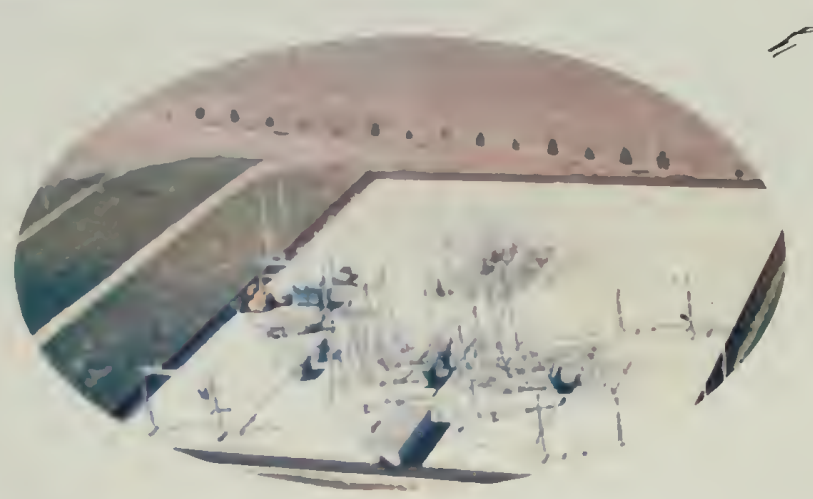

In other studies, statistical methods are being used to analyze existing geological and mineral data, and field studies are being made using classical geological methods. Surveys making limited use of geophysical methods such as gamma-ray spectrometry and the magnetometer are also being conducted. 


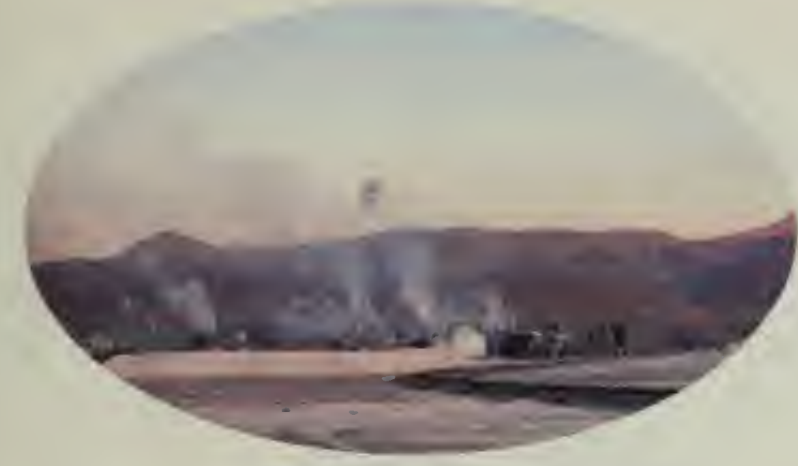

Mining of nonmetalic commodities such as talc, feldspar, clay, borates, sand and gravel, and salines (salts), as well as the "rare earth" elements, is an important industry at this time in the CDCA. Exploration for other very important commodities like uranium, lithium, and copper, is also being carried on extensively. It is vitally important that a thorough understanding of the G-E-M resources in the California desert exists in order to have a realistic multiple-use plan.

National attention has also turned to the California desert as the emphasis on energy sources grows. Several areas with geothermal potential are known. One is presently being developed and several smaller sites are being studied. It is estimated that by the year 2000, a substantial portion of California's total electricity might be derived from geothermal sources. Several sites proposed for power generation, both thermal and nuclear, are being studied for possible construction over the next decade. Many of these sites are on public lands, and all would involve transmission lines crossing the desert.

In addition, because of its climate and open land, the CDCA also has outstanding potential for using solar energy. Several pilot projects are underway, and significant research and development funds have been allocated for this purpose by the Department of Energy.

It was mineral resources and mining that first brought this desolate area into national focus. Gold and silver were responsible for drawing thousands of prospectors who extracted these precious metals from isolated mountain ranges and river areas. Today, however, many other minerals are being mined and many others are known to exist. It is estimated that by 1980 the mineral production

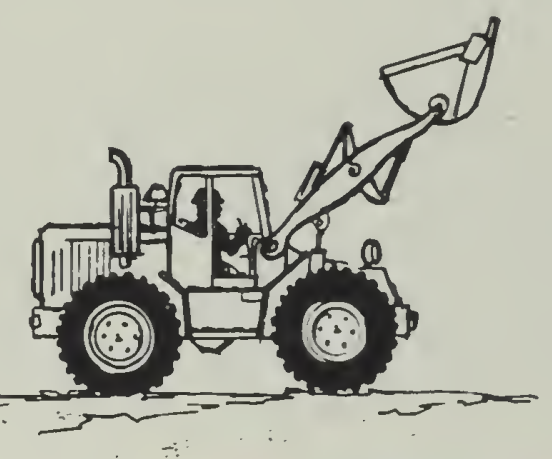
from the CDCA will surpass 300 million dollars annually.

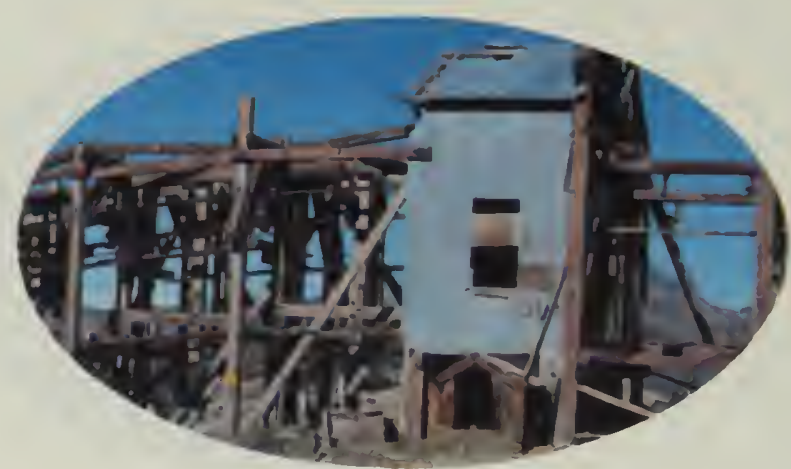


Approximately 1,500 species of flowering plants grow in the California desert, and many of them are found nowhere else in the world. Aside from their scenic value, they offer great potential in the field of medical science; are significant in the study of plant evolution; and are essential as forage. Roughly 130 species appear on Rare, Threatened, or Endangered lists.

Inventories of desert vegetation have been much neglected in the past. Careful vegetation mapping is vital for allocating wildlife habitats, grazing areas, recreation-use areas, utility corridors, etc. It is in potential areas for these uses that the most extensive inventorying efforts are being devoted. Early studies show considerably wider distribution and greater number of important botanical resources than were known to exist. New populations of rare plants, previously believed to exist in a single area, have been located in other regions.

Approximately 9,000 cattle and up to 15,000 sheep currently forage on lands administered by the Bureau of Land Management. Estimates are that about one-fourth of the CDCA is grazeable, though this figure varies seasonally, and from year to year, dependent upon the amount of rainfall. Allocations of forage for this use in relation to other demands must be carefully planned to maintain long-term sustained yield.
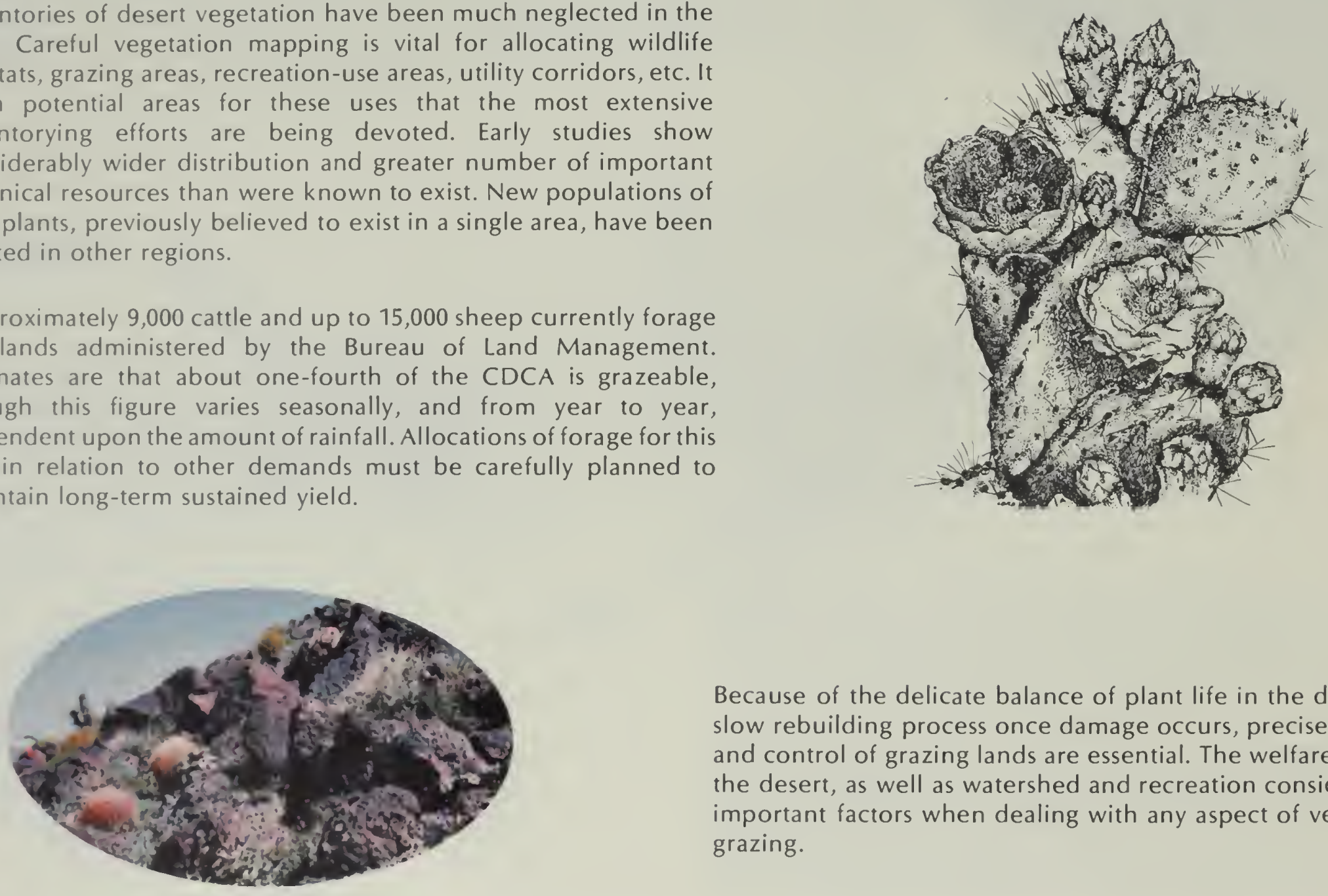

Because of the delicate balance of plant life in the desert and the slow rebuilding process once damage occurs, precise inventorying and control of grazing lands are essential. The welfare of wildlife in the desert, as well as watershed and recreation considerations, are important factors when dealing with any aspect of vegetation and grazing. 
As with several other resources, LandSat imagery and U-2 color photos used in conjunction with detailed information already compiled from the four previously inventoried planning units are expected to play a major role in vegetation mapping. Ground checking will be used extensively to verify remote sensing results.
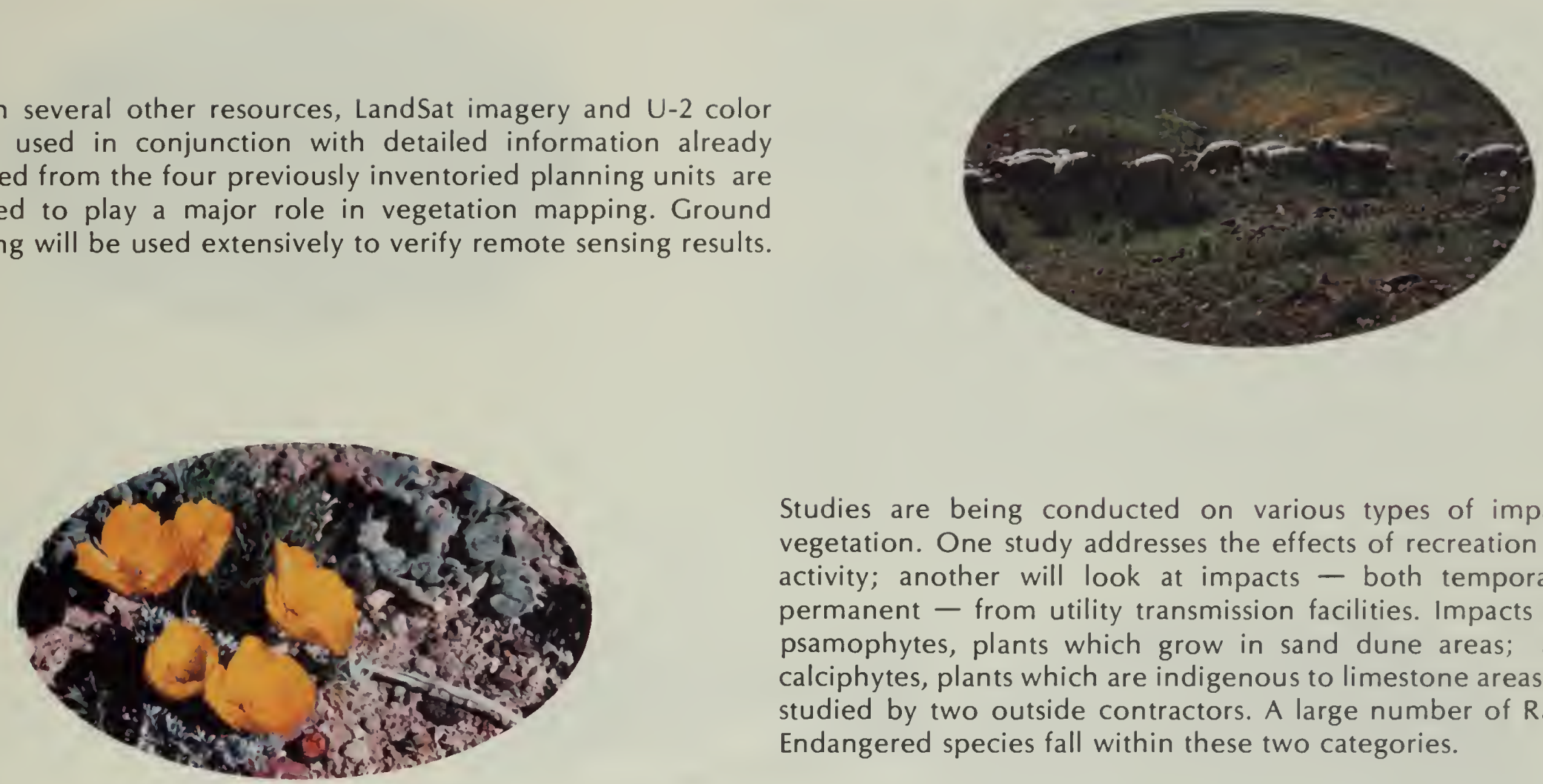

Studies are being conducted on various types of impacts on vegetation. One study addresses the effects of recreation vehicle activity; another will look at impacts - both temporary and permanent - from utility transmission facilities. Impacts on rare psamophytes, plants which grow in sand dune areas; and on calciphytes, plants which are indigenous to limestone areas, will be studied by two outside contractors. A large number of Rare and Endangered species fall within these two categories.

General changes and trends in vegetation patterns are constantly occurring, and indications of these give clues to changes in man's life styles, as well as those in the climate. Juniper remains, for example, and remnants of other vegetation have been preserved and discovered in the dens of pack rats hundreds of miles from where such vegetation now occurs. Such Presettlement and Postsettlement vegetation studies have interesting archaeological and anthropological implications.

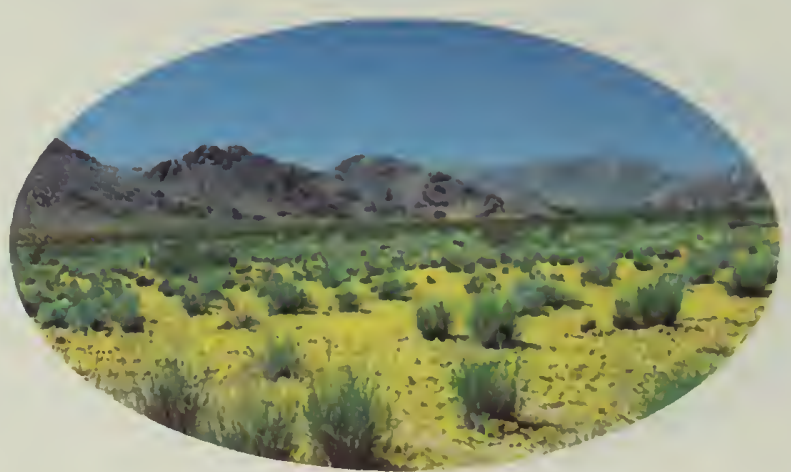


When the fragile environment of the California desert is mentioned, reference is frequently being made to its shallow soil mantle. Many desert soils are extremely productive, and support many species of unique vegetation. These same soils are excessively vulnerable to erosion, by wind as well as water, and to damage by vehicular traffic.

The need for land with soils capable of producing vegetation, forage, and agricultural crops continues to increase. Such lands must be identified and managed to conserve them for future use. Extensive surveys have been conducted in four Management Framework Plan areas covering broad soil groupings, associated vegetative species, and physical and chemical properties. Three more areas will be inventoried shortly.

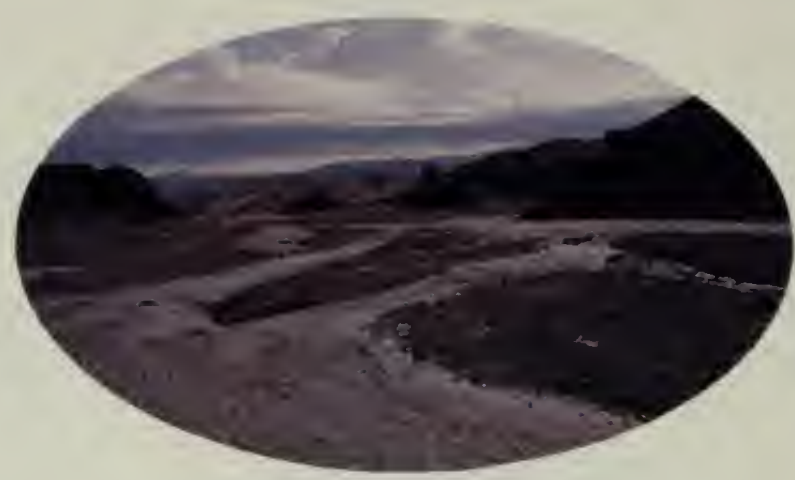

$A_{\text {ir }}$
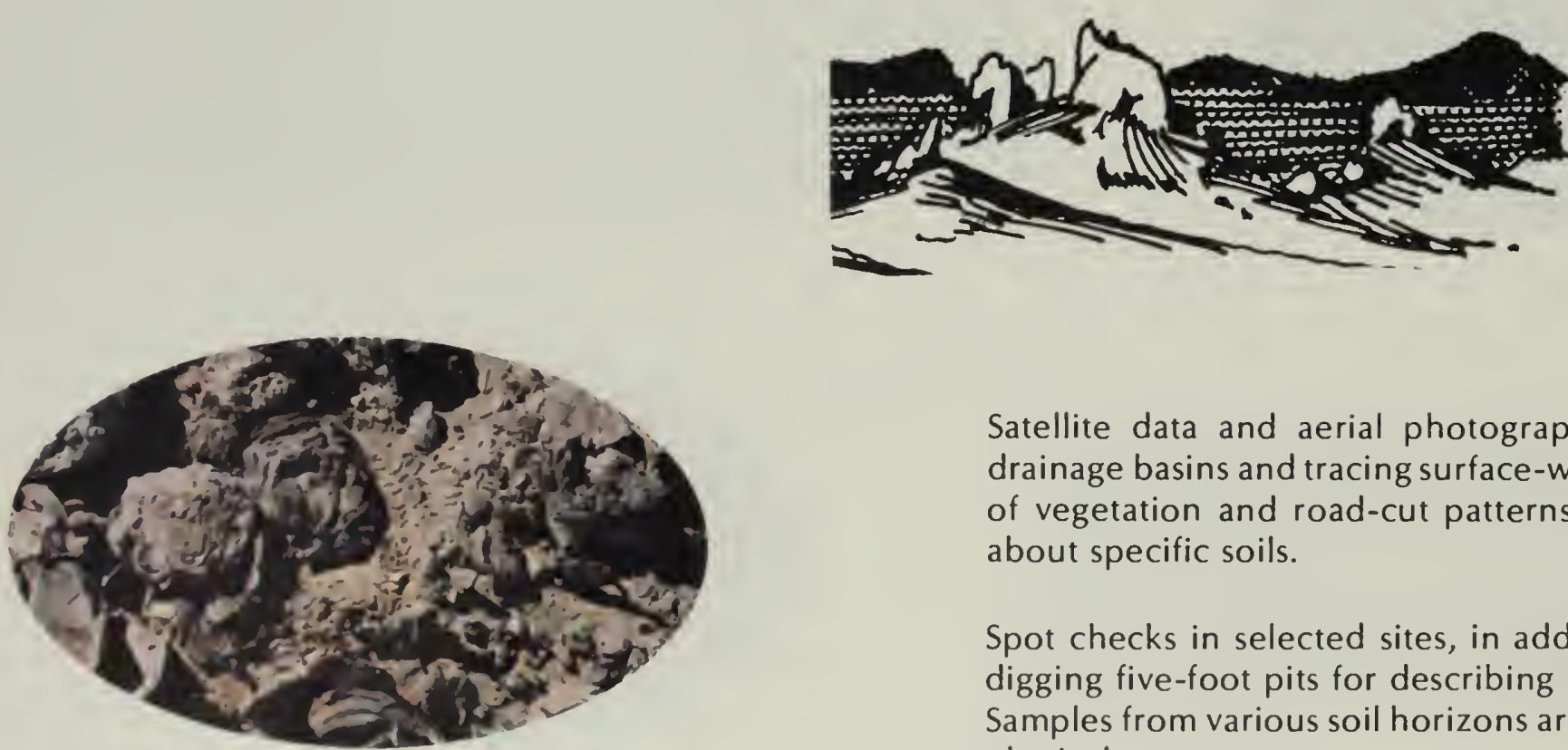

Satellite data and aerial photography are aiding in outlining drainage basins and tracing surface-water patterns. Shading, types of vegetation and road-cut patterns shown give valuable clues about specific soils.

Spot checks in selected sites, in addition to core drilling, entail digging five-foot pits for describing soil profiling in great detail. Samples from various soil horizons are lab tested for chemical and physical parameters. 


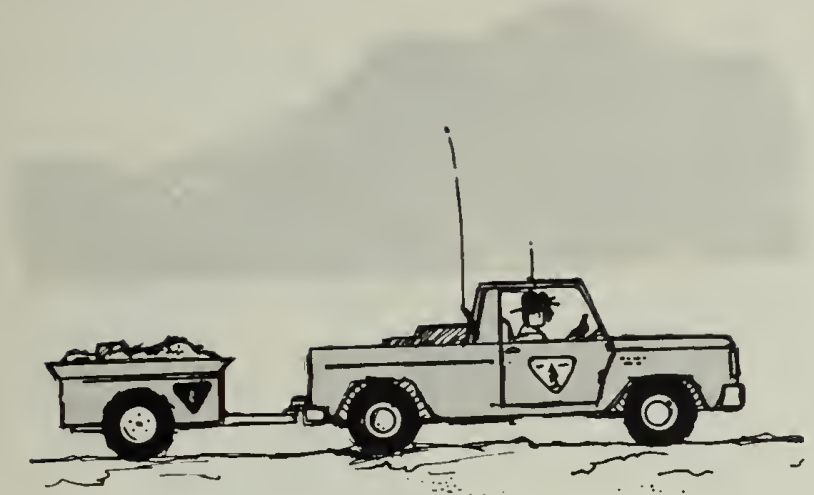

Studies are being performed to determine the present air quality, including investigation of the possible airborne transport of valley fever spores and other potentially toxic materials. This is being done by personnel from DPS, Arizona State University, and the National Center for Atmospheric Research. If these materials are spread as a result of soil disturbances, desert-land-use management may be significantly affected.

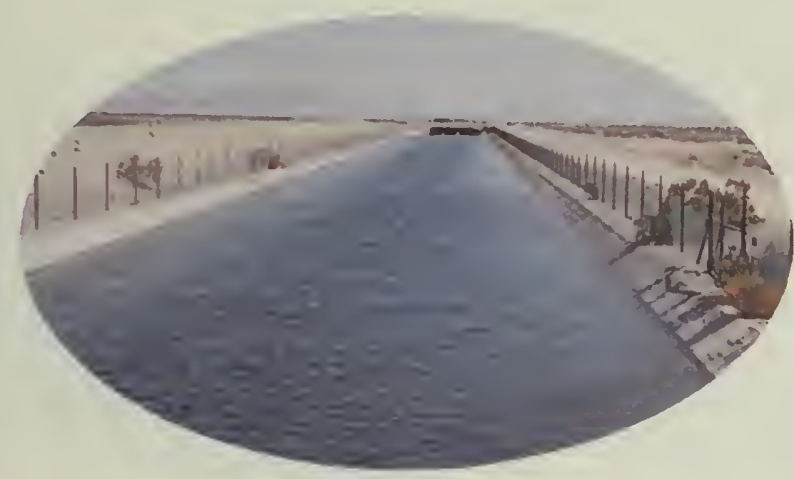

In the Lucerne Valley and elsewhere, a series of soils impact studies to determine the effect of surface disturbance by vehicles are being conducted. Pick-up trucks, four-wheel-drive vehicles, and motorcycles are periodically run over sites comprised of different soil types. Soil strength tests, staged at various intervals following rainfall, are compiling data that will be used to evaluate impacts in other areas of the desert.

Data needed to describe surface- and ground-water supplies are being obtained through a cooperative agreement with the U.S. Geological Survey. Information on existing wells, springs, and stream gaging stations throughout the CDCA will be stored in the DPS computer.

A survey of water-related programs of governmental and private agencies within the CDCA is in progress.

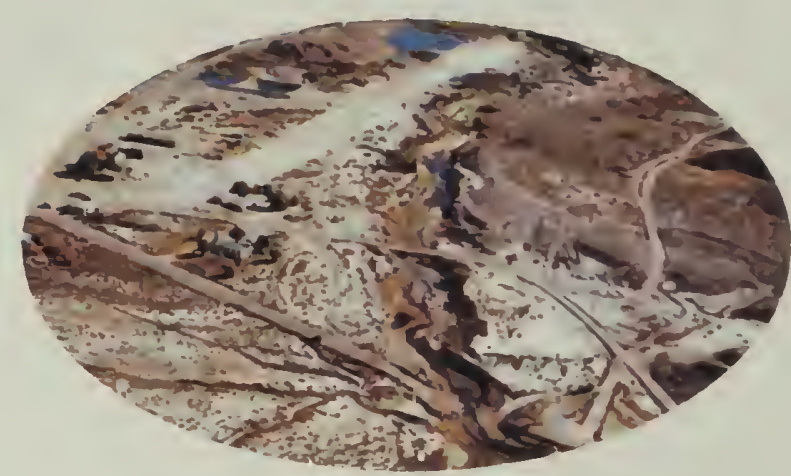

Close coordination is being maintained with the California Air Resources Board, Environmental Protection Agency, and local and county air quality districts. Data on existing air quality levels and pollutant emissions is being provided by these agencies for input to the DPS computer. 
Webster defines recreation as "the refreshment of strength and spirits after work." Qualifying under this definition are roughly 27 activities in which people regularly indulge in the California desert. If you're of the "have to blow off steam" set, try motorcycle racing or hill-climbing, hang gliding, sand sailing, horseback riding, dune buggying, or scale some of the desert's rock formations. If contemplation or solitude is your thing, opportunities for picnics, nature study, historical research, archaeology, wildflower and wildlife observation and a host of more passive pursuits abound.

No one can assign a dollar figure to the worth of the California desert as a vast playground for the millions of people living within easy driving distance. But for many, the value of the myriad unique recreation experiences outweighs that of all the other resources lumped together. The number of annual visitor-use days (VUD's) has been estimated as high as 14 million. Recent quantitative studies by the Desert Plan Staff point to a figure between two and four million as being more realistic. Regardless of the exact figure, use of the desert by recreationalists justifies close scrutiny and careful planning.

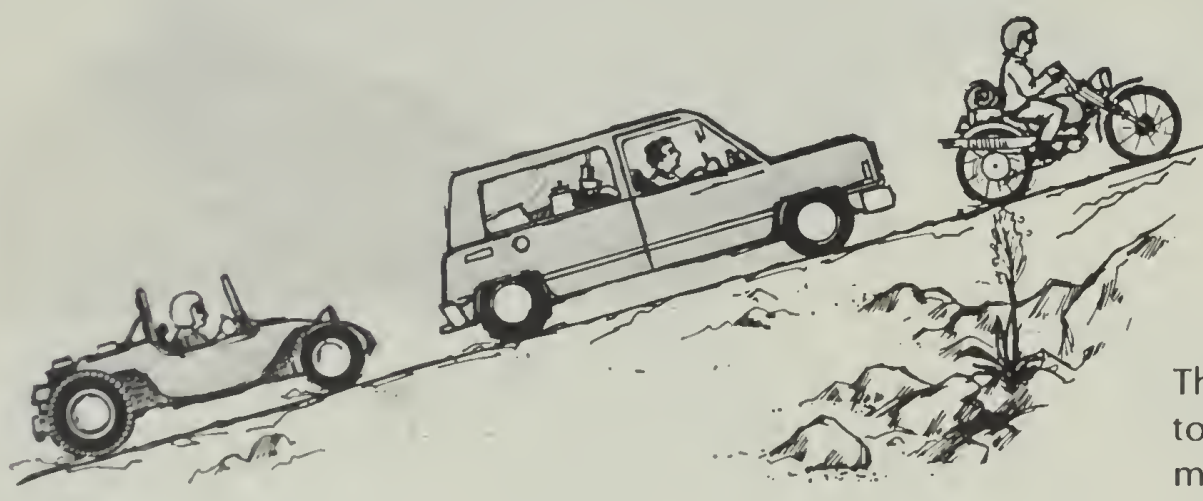

The recreation resources team of DPS has made a vigorous effort to expose to a broader public the nature of a major land management assignment. Rather than arbitrating the differences voiced by two less-than-harmonious groups, e.g., recreationvehicle enthusiasts and conservationists, in the classic, local, town-hall setting, it took the tack of contracting several extensive surveys that would clarify the overall montage of desert recreation. 
The Organized Recreation Group Study, for example, disclosed that at the top of the recreationists' concerns were the conflicting issues of too much governmental control and excessive use of the desert by off-road vehicles. Ranking high in "satisfactions" were comaraderie, escape from civilization, communion with and appreciation of nature, family togetherness, and competition. In total, 400 southern California groups having a combined membership in excess of 102,000 were surveyed.

Another survey, a nationwide Gallup Poll, disclosed that 17 percent of the country's public had been to the California desert - higher than previously realized. Most relayed strong concern for the protection of wildlife and general ecology, desert scenery and natural character, historical and archaeological sites. These findings varied only slightly from those of two statewide Field Polls.
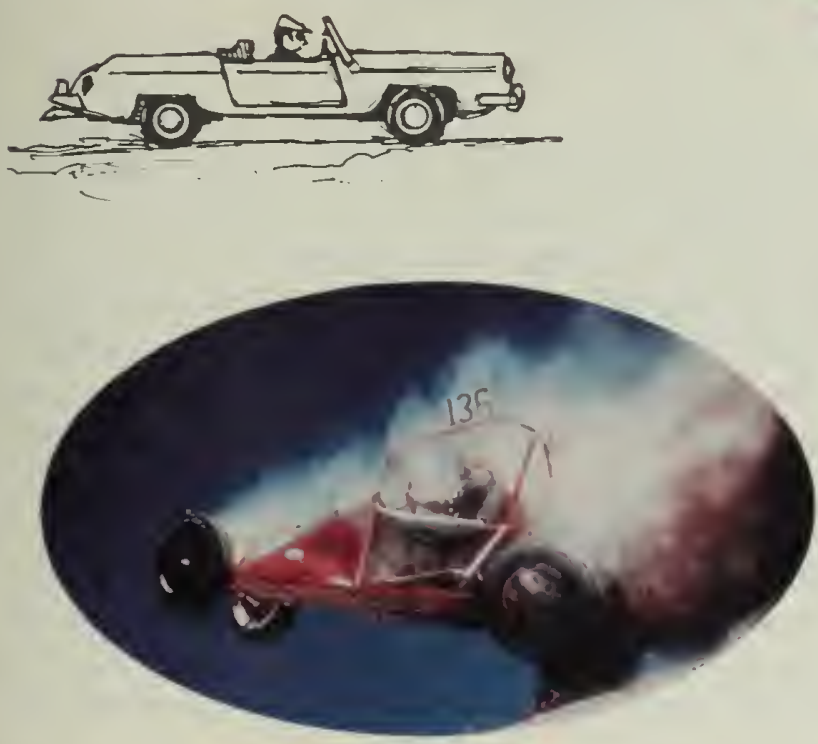

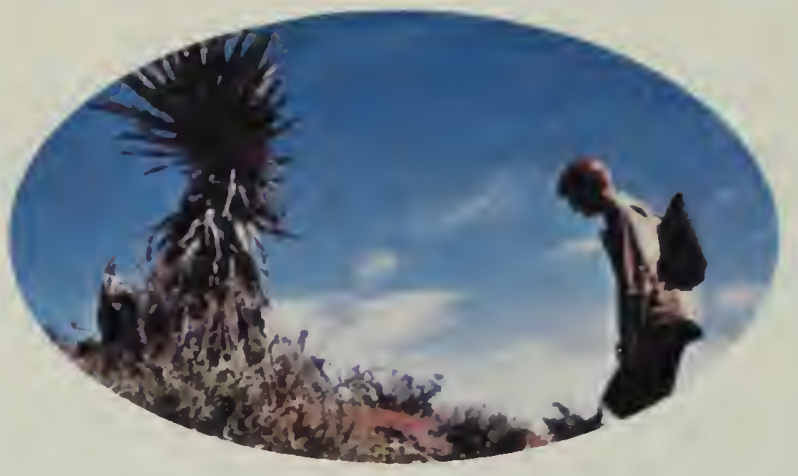

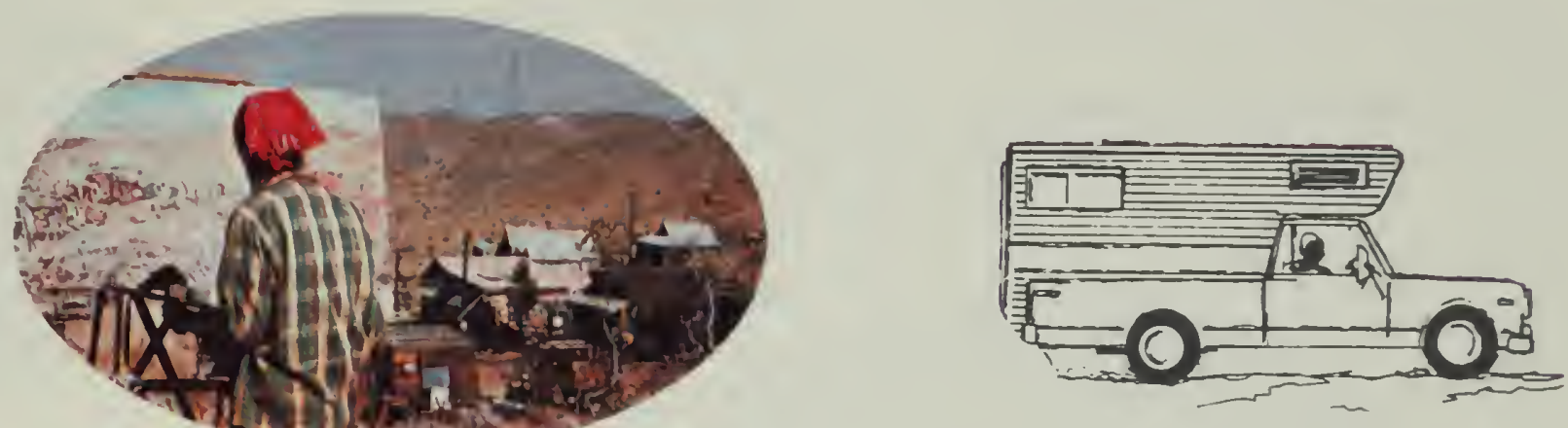

In the realm of scenic/visual quality, the inventorying process involves the designation of approximately 350 areas with ratings based on land form, color, variety, and several other parameters. Frequency and nature of use presently made by recreationists in the desert are being sampled by another contract calling for bi-monthly on-the-spot visits to 180 commonly used sites. Also, 26 times per year, low-altitude aerial observations by BLM personnel check the degree of use of various recreational sites and facilities. Vehicles are counted and a quantitative assessment is made.

There is a limit to the number of recreationists and types of activities that an area can support before the quality of the environment or the recreational experience becomes impaired. A study developing "carrying capacity" concepts is completed. Also, initial studies to determine preliminary wilderness study areas are underway. Involved are roadless areas comprised of 5,000 or more acres which have wilderness characteristics. 
The California desert is rich in clues to past cultures. Thousands of known sites contain remains that tell how people lived, worked, defended, and amused themselves. Undoubtedly, many times that number have yet to be discovered. And when they are, they are expected to shed useful information on some of the problems we face today.
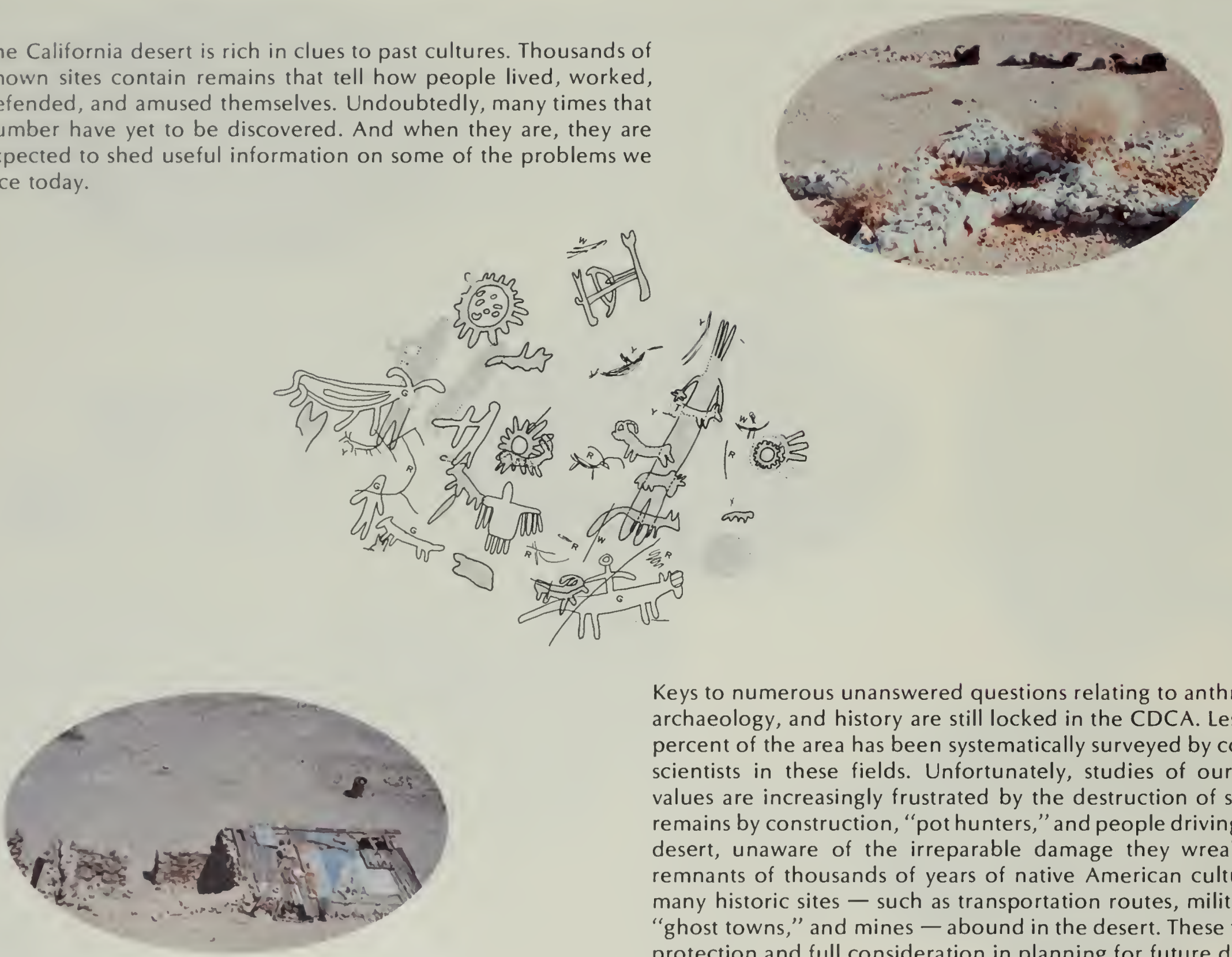

Keys to numerous unanswered questions relating to anthropology, archaeology, and history are still locked in the CDCA. Less than 10 percent of the area has been systematically surveyed by competent scientists in these fields. Unfortunately, studies of our heritage values are increasingly frustrated by the destruction of significant remains by construction, "pot hunters," and people driving over the desert, unaware of the irreparable damage they wreak. Fragile remnants of thousands of years of native American cultures, plus many historic sites - such as transportation routes, military posts, "ghost towns," and mines - abound in the desert. These too, need protection and full consideration in planning for future desert use. 
Division of the CDCA into clusters of planning units has been undertaken by the Desert Planning Staff. These will be inventoried in a two-phase operation. After completion of the random, or reconnaissance-level sample inventory, an intensive analysis phase should result in a comprehensive report dealing with the sensitivity of sites and areas, present and future potential impacts, and recommended safeguards or mitigations.

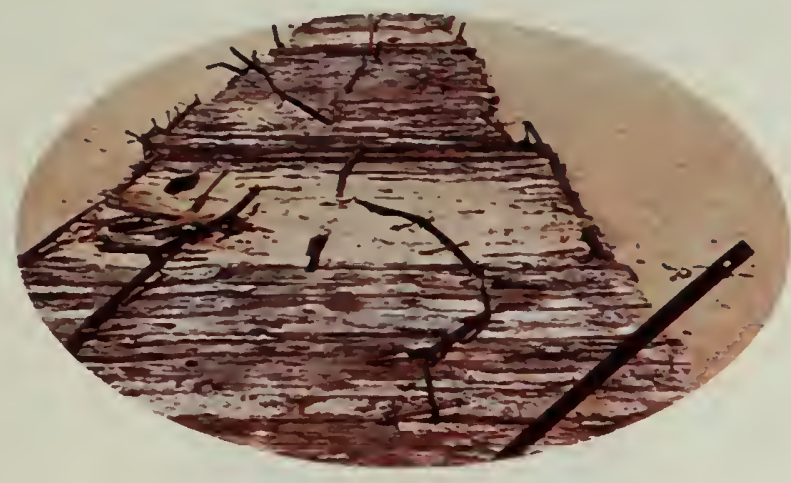

Final result of the multi-stage effort will be the development of a prehistoric and historic land-use model. Inferences and explanations of behavior during these periods are expected to complement the model. Initial work has already resulted in a number of unexpected discoveries. It now appears that site density, or the number of prehistoric or historic sites in the desert, is four to five times greater than previously realized by most researchers.

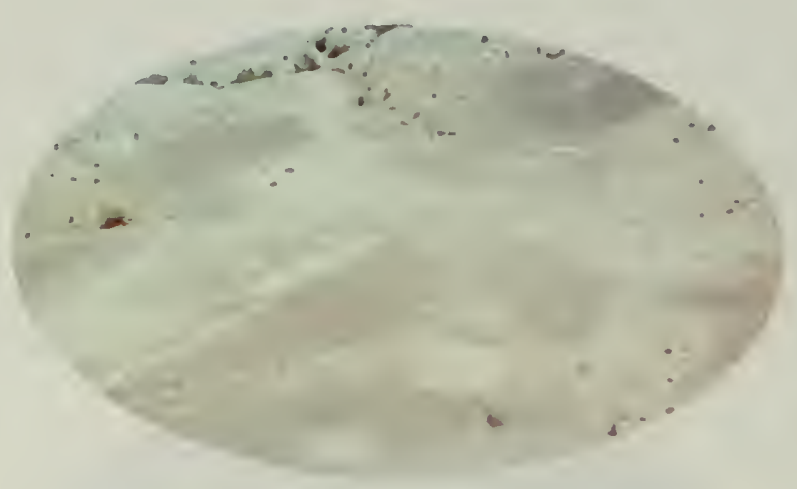

Secondly, many sites are being located in areas of the desert where none were expected. Encampments, rock-art locations, and sacred native American areas, for example, have been located or reported on mountain tops formerly believed barren or unimportant. Intaglios, or desert-pavement figures, have been spotted on many of the terraces of the Colorado River. And at great depths along unlikely arroyos, possible indications of very early peoples have been located.

Many of the recent finds are uniquely preserved. Intaglios and multi-colored rock-art sites are virtually pristine in some areas. Camp sites, believed to be a thousand years old, appear as though abandoned only a few years ago. 


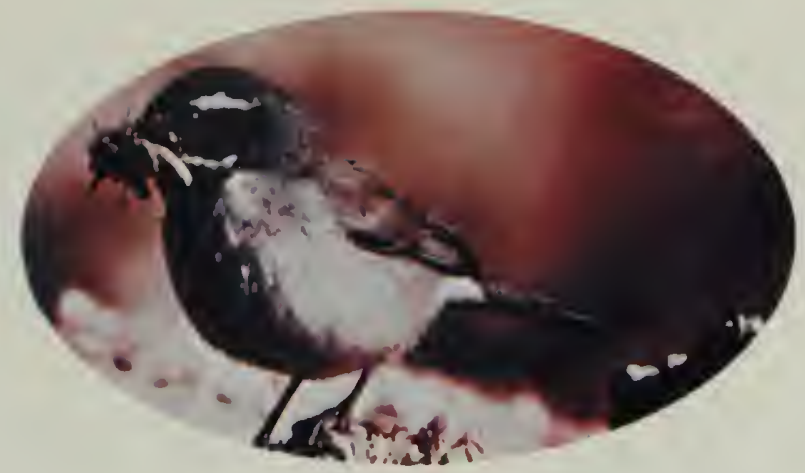

Topping the list for public concerns about California desert resources is wildlife, according to a recent Field Poll. People care about the dwindling populations of many rare species; for example, over 30 species of western U.S. fish have become extinct within the past 20 to 30 years, and the urban encroachment is adding to the list annually. About 500 species of vertebrates and thousands of species of invertebrates make their homes in the CDCA.

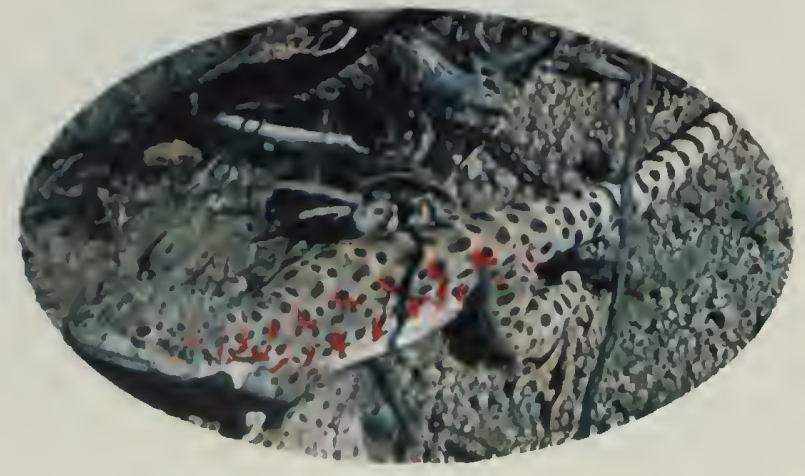

The ratio of visits in the area for hunting, to those for nonconsumptive uses such as viewing, scientific study, and photography is about two to three, and dropping. Important upland game include quail, chukar, dove, and rabbits, with deer being the main big game species. But increasing numbers of visitors come just to catch a glimpse of the rare bighorn sheep, golden eagle, prairie falcon, or desert tortoise.

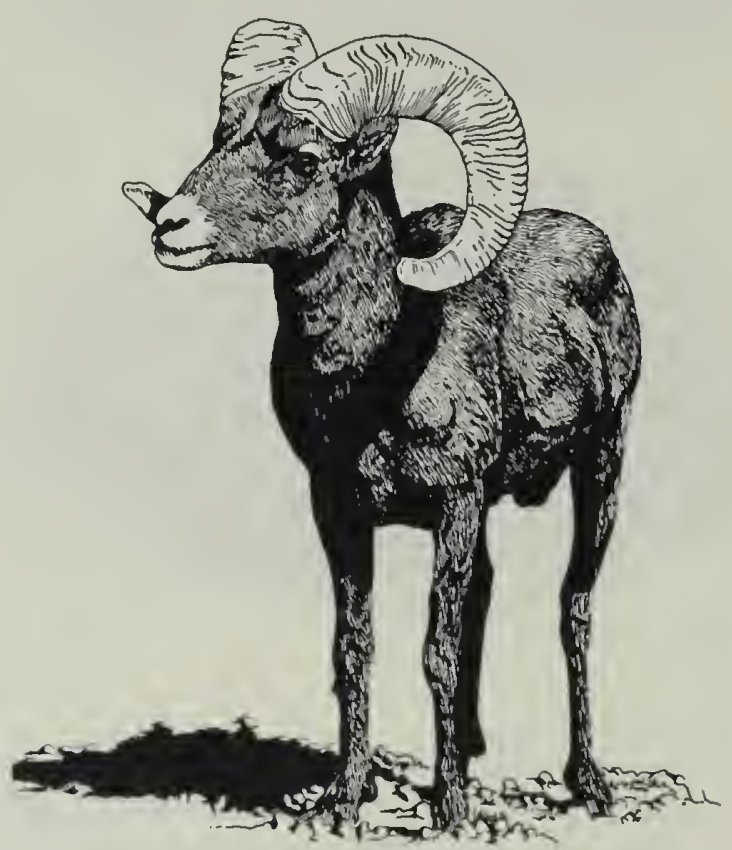

While some eyebrows raise at the mention of fish in the desert, some of the heaviest angler use in the state is at desert fisheries. Fish thrive in the Salton Sea and its tributaries; in the lower Colorado River complex; and in the canals, ditches, and periferal streams near the desert's western edge. A variety of threats exist to fish populations in the desert with the increasing salinity of the Salton Sea being the most severe. Excessive pumping of groundwater nearly exterminated the only school of Devil's Hole pup fish now in existence - until the courts took needed action. 
The number of desert wildlife "classrooms" and research project sites is continually growing. Here again, protective measures are needed. University and high school groups which have made periodic treks to a favorite site and set up various monitoring devices to study particular species have frequently discovered habitat areas totally devasted.

Wildlife studies by the DPS team are divided into three phases. The first includes a thorough literature search, acquisition of museum records, the compilation of unpublished field notes and data, and personal contact with scientists having past and current research projects in the desert. All material is processed for storage in, and quick retrieval from, the DPS computer.

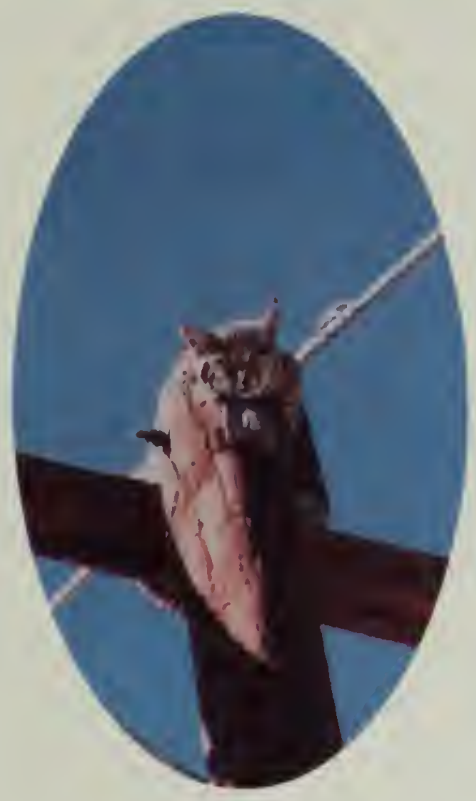

In addition, a survey of predatory birds revealed several new golden eagle and prairie falcon eyries, and provided urgently needed information about the general distribution of raptors throughout the California desert.

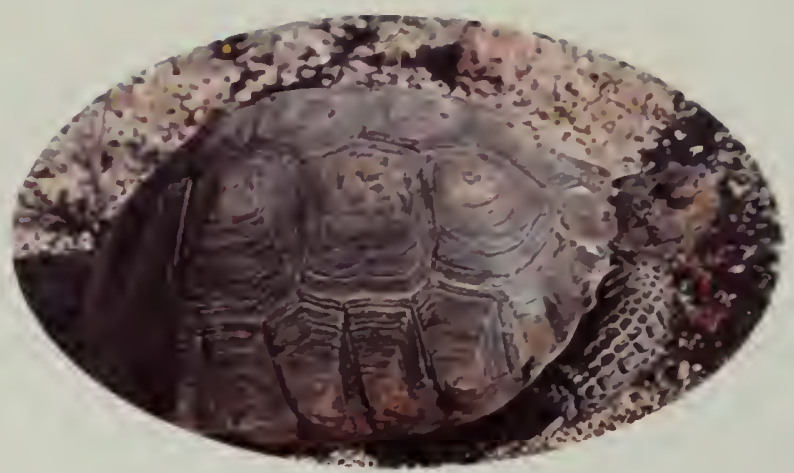

Preliminary identification of potentially sensitive and critical wild life habitats has been completed. Close cooperation with specialists in vegetation, soil, watershed, and recreation has been stressed throughout. Emphasis during the second phase is on field work in which the primary effort is aimed at intensive survey of these areas. Some interesting findings already noted include an isolated population of dusky-footed wood rats 100 miles distant from the nearest previously known group; an addition of 1,800 square miles to the known range of the Mojave ground squirrel; and discovery of the Yuma clapper rail hundreds of miles away from where they had been previously known to exist.

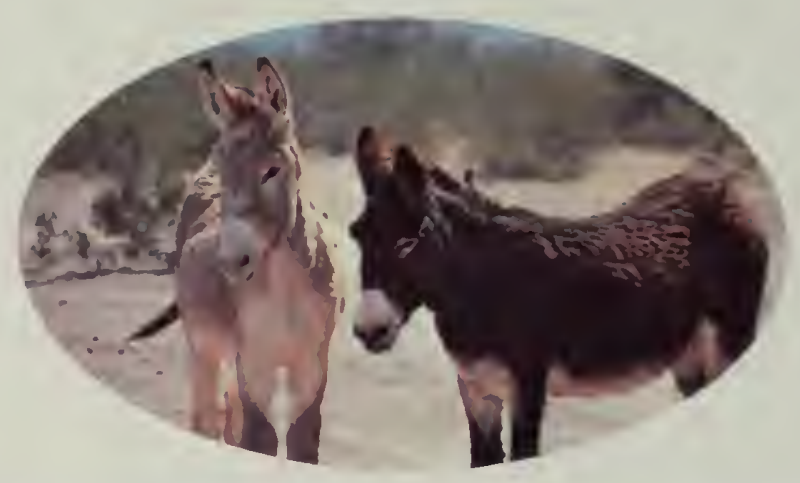




\section{Policy}

The planning process is guided by laws and regulations established to assure wise use and protection of natural resources. In the Federal Land Policy and Management Act of 1976, Congress declares that public lands be managed on the basis of multiple use and sustained yield unless otherwise specified by law.

Multiple use is defined as the management of public lands and their various resource values so that they are utilized in the combination that will best meet the present and future needs of the American people. It also calls for the most judicious use of the land for some or all of these resources or related services over areas large enough to provide sufficient latitude for periodic adjustments in use to conform to changing needs and conditions.

Sustained yield means the achievement and maintenance in perpetuity of a high-level annual or regular periodic output of the various renewable resources of the public lands consistent with multiple use.

Other laws that must also be adhered to in developing the California Desert Plan include:

- National Environmental Policy Act of 1969

- Mining Law of 1872

- Mineral Leasing Act of 1920, as amended

- Executive Orders No. 11644 and 11989 and

Regulations, CFR Title 43, Part 6290 on

Off Road Vehicles

- Wilderness Act of 1964

- Antiquities Act of 1906

- Historic Sites Act of 1935

- Endangered Species ACl of 1973

- Clean Air Act, as amended

- Fish and Wildlife Coordination Act

- Taylor Grazing Act of 7934

- Federal Water Pollution Control Act

- Safe Drinking Water Acl

\section{Inventory E Analysis}

All resource inventory data is stored in the DPS computer for use in analysis, frequently involving high-speed tabulations. For example, what species of wildlife are found in various habitat types? There are over 100 wildlife habitat types, and the computer can print out the individual species found in each type.

The analysis is designed to provide answers to questions relating to allocations of land within the framework of Bureau policy. Various analyses aid in determining such factors as:

- Opportunities for future use and enjoyment

- Capacity or capability of the area to sustain an activity

- Significance of the site compared to other sites with the same resources

- Sensitivity of a particular resource to various forms of use

- Supply-and-demand relationships between a resource and its use, both present and to the year 2000

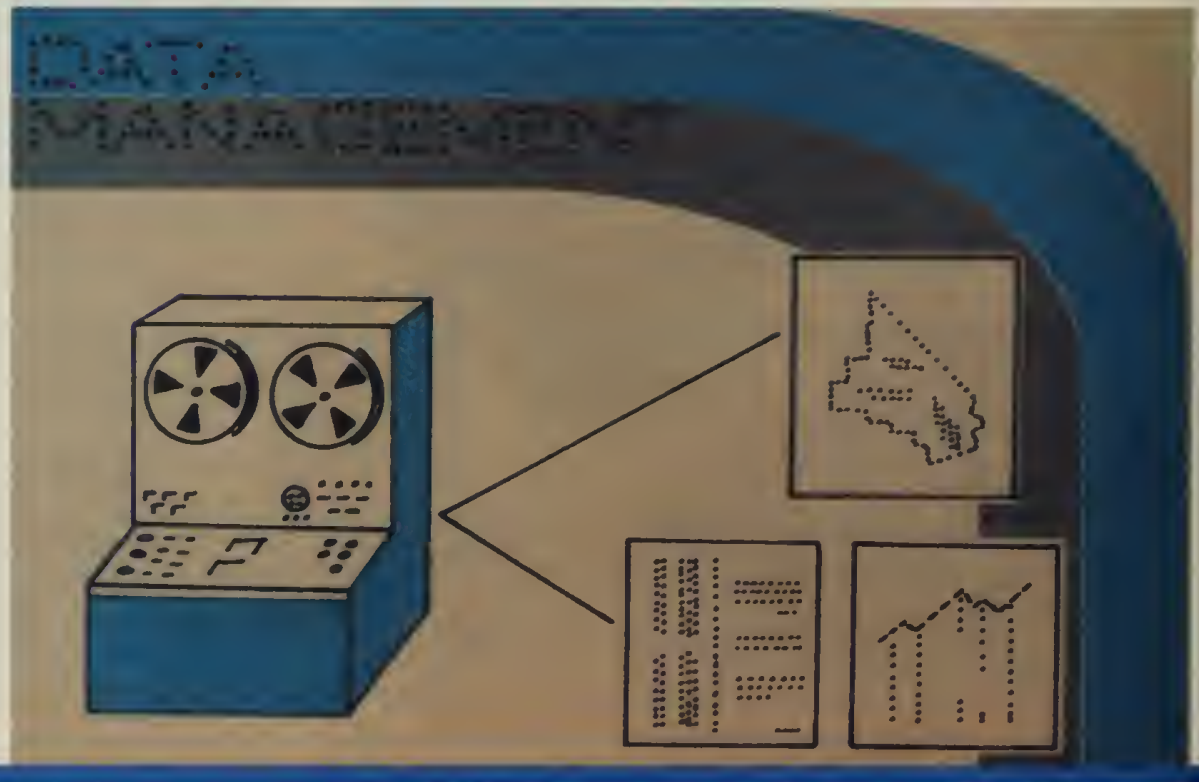


The draft plan and the accompanying Draft Environmental Statement will be prepared by DPS and submitted to the public for review and comment in early 1980.

Form and substance of the plan will be basically an allocation of land for both its use and protection. Management objectives for various categories of allocation will be established. The present Interim Critical Management Plan is an example of allocation of land for vehicular use. The categories are "open," "closed," and "restricted" use. The California Desert Plan will be as comprehensive as possible, and allocations for uses such as grazing, utility corridors, wilderness, protection of cultural areas, urban expansion, and other uses will be included.

The draft plan will provide alternative land-use allocations in areas where conflicts between resources occur. The environmental analysis will provide an assessment of the impacts or consequences of each alternative on resource values, the environment, the economy, the social/political framework, and management of resources.

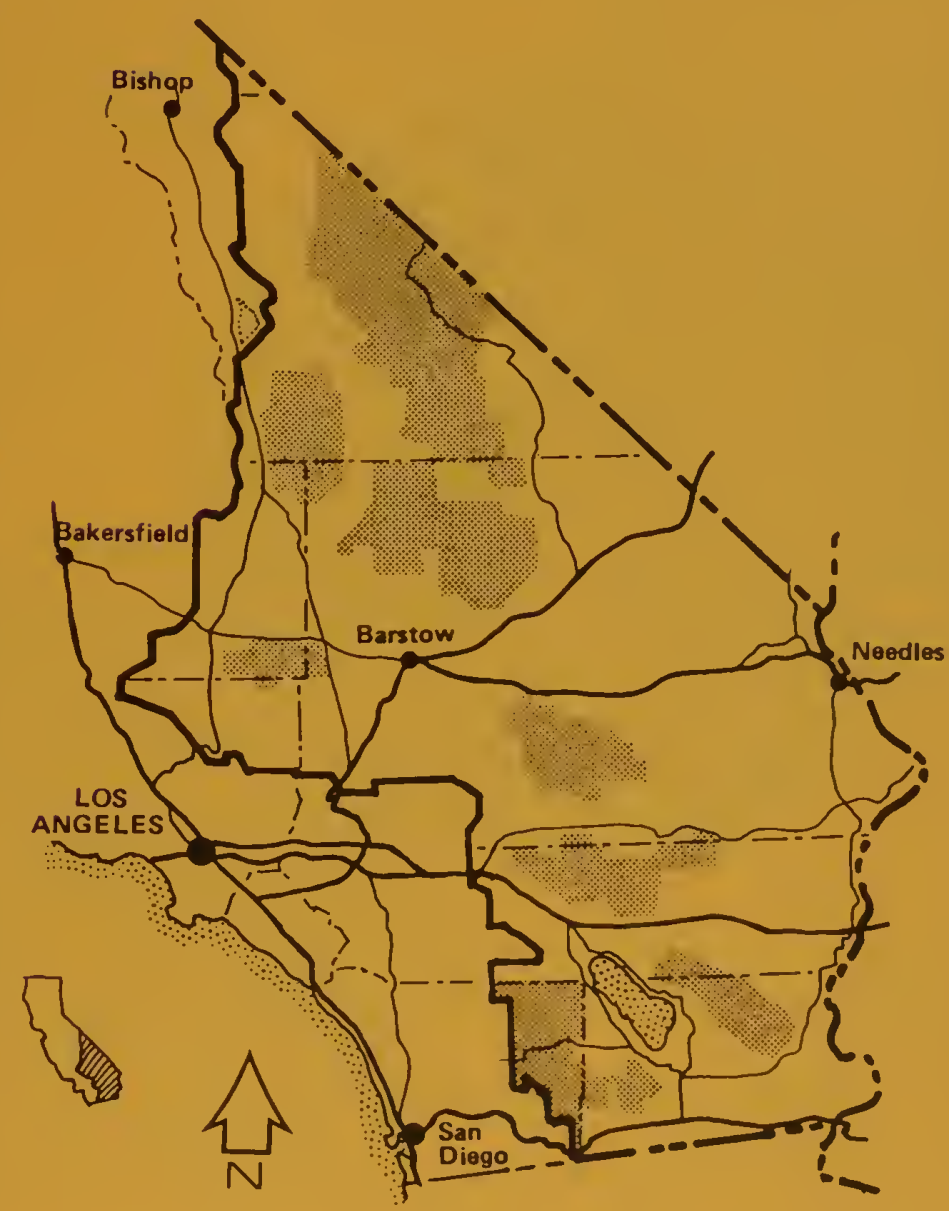

The final plan will be prepared after careful evaluation of public input on the draft plan.

It is expected that the final plan will project the best compromise between competing interests within the framework of law and policy. A balanced desert-wide view of supply (resources and land) and demand (use by man) will be provided.

The plan looks to the future and considers the needs of the next generation and successive generations, and the pressure that growth and new technology will bring.

The plan will provide a realistic framework for present and future management and will be the basis for detailed plans and for establishing priorities among programs which must compete for limited funds.

It is not, however, a static product. The planning process is continuous. The program is set in motion, i.e., coordination with other agencies, inventory of resources, public participation, analysis and land-use-decision evaluation procedures will continue to operate in a new mode that monitors change and provides for course corrections. 


\section{PARTICIPANTS}

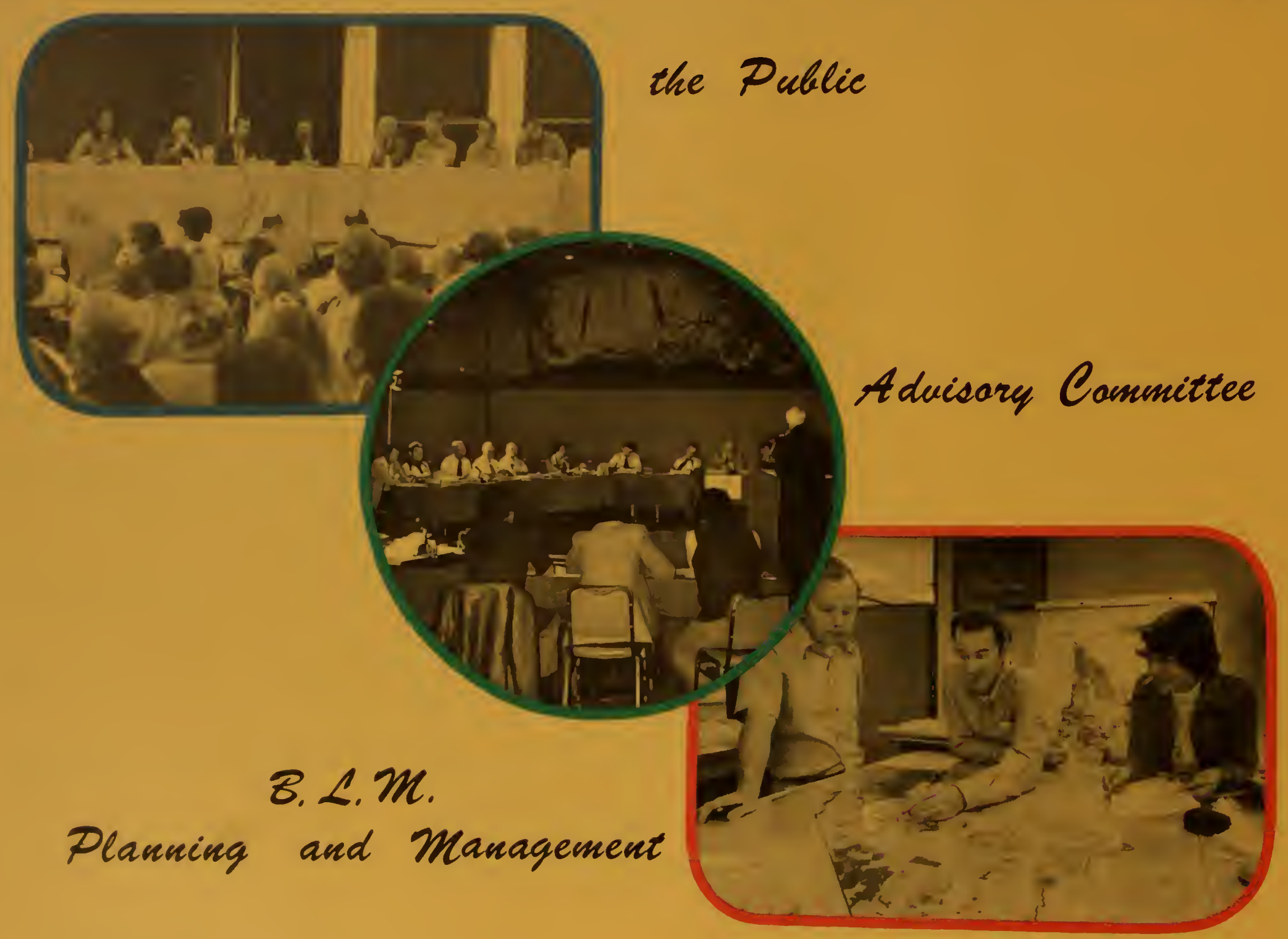


A vital fact of the desert plan program is public participation. Since the

\section{Participation} public owns the land in question, it should play a major role in any decision affecting it. The purpose of the public participation plan is to provide open and continuous communication between various "publics," the Advisory Committee, and BLM. "Publics" generally fall into three classifications: general public, interested individuals and organized groups, and desert residents. All can offer valuable data, opinions, and suggestions on objectives and goals for the program.

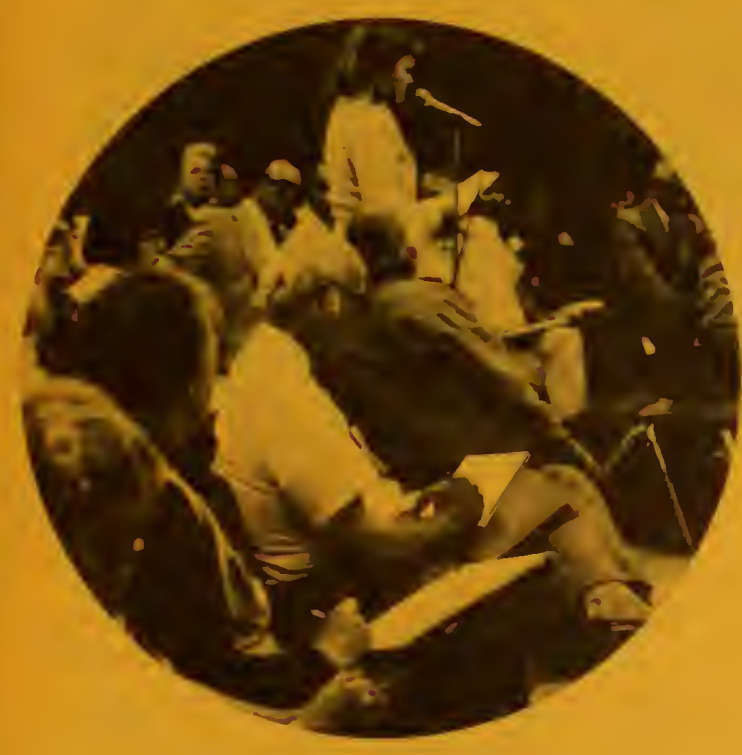

Public participation is closely keyed to all phases of the desert plan. During the initial years, it was decided to emphasize public information and obtain data concerning values, interests and suggestions, focusing on the various resources involved. Also, because a comprehensive desert plan was in preparation, the need for public involvement

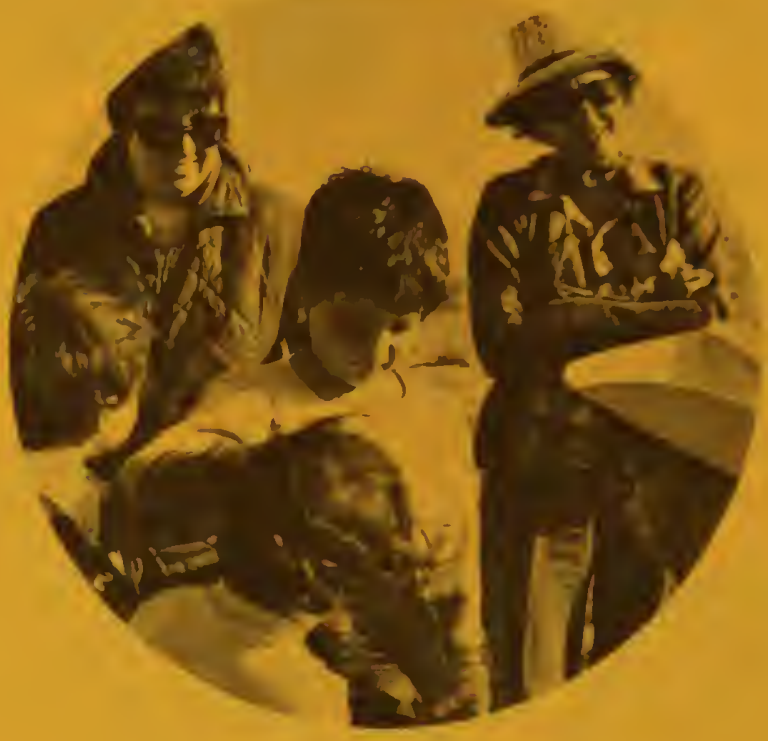
during that period had to be stressed.

Public involvement would increase in scope through November 1978. For example, many individuals have resource knowledge, such as locations of springs, rockhounding areas, and historical areas, which would augment DPS's information. Others might want their feelings known about how the public lands of the desert should be managed. This is all welcome input.

From October 1978 until publication of the "draft" Desert Plan, public input would be evaluated and incorporated. After publication of this document and until the "final" Desert Plan is published, emphasis would again be placed on the information and education of the public-participation plan. 


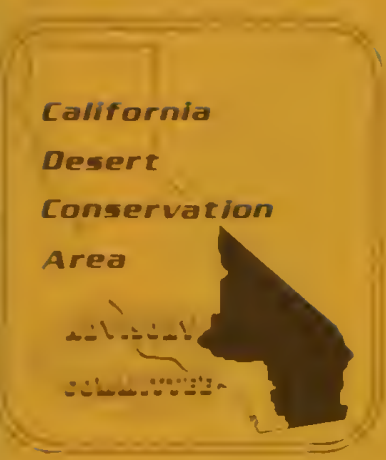

JAMES W BLRNS

Sute Government

FRASK \& DELORE

Energy Utilties

* LEON HLNTLR

Envi-nmental Scrence

RICHARD H JAINS

farth Scrence

LALRI VCE H LAYE, Jr.

Pubi= Affars

I DEAN LEMOS

Muning Manerals

WILBUR W MAYIIEH

Widure Resources

HARIEY PIRLOTF

Socul Scrence

WILLII PLVK

General Public

(Quatuve Americans)

CLAYTON A RECORD, J,

Flected General-Purpose

$G$ vernment

ERNA SCHLILINC

General Public

RLTH SIMPSOS

Archaeolory

ROYALD I SLOA:

Ouidool Recteation

GF NVY SYITH

Outdor Recteation

RICHARD VOGL

Botancal Reworcev

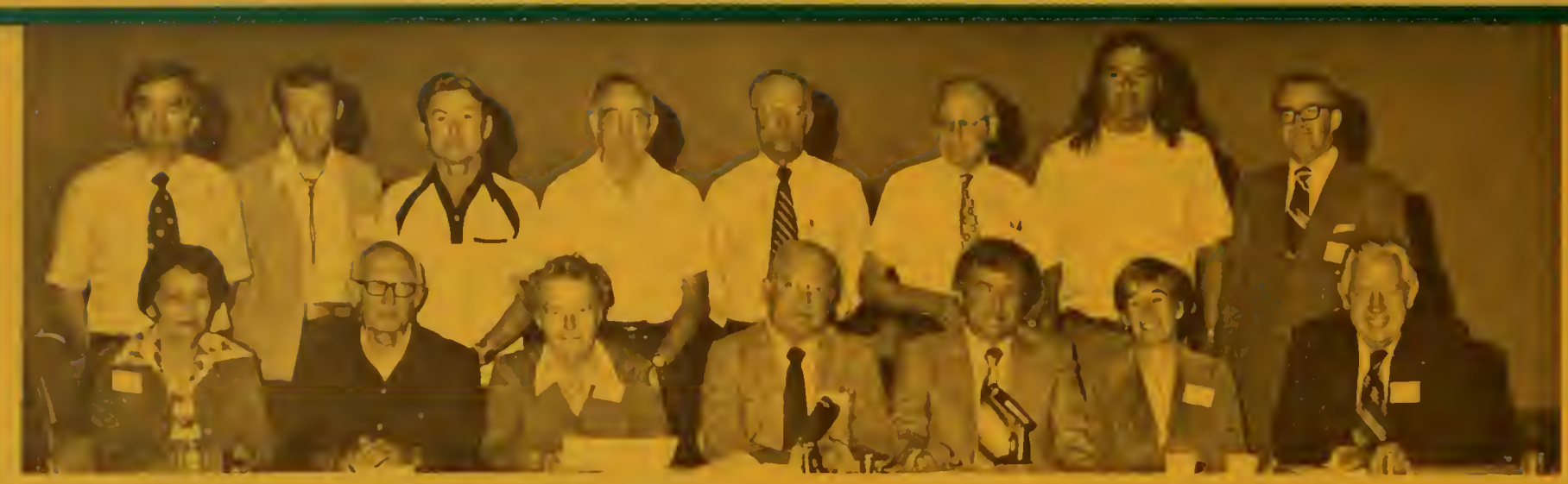

A panel of 15 experts in a variety of specialties serves as the California Desert Conservation Area Advisory Committee, and plays a major role in the preparation of the desert plan. As citizens vitally interested in the welfare of the desert, they advise the Secretary of the Interior in all aspects of the
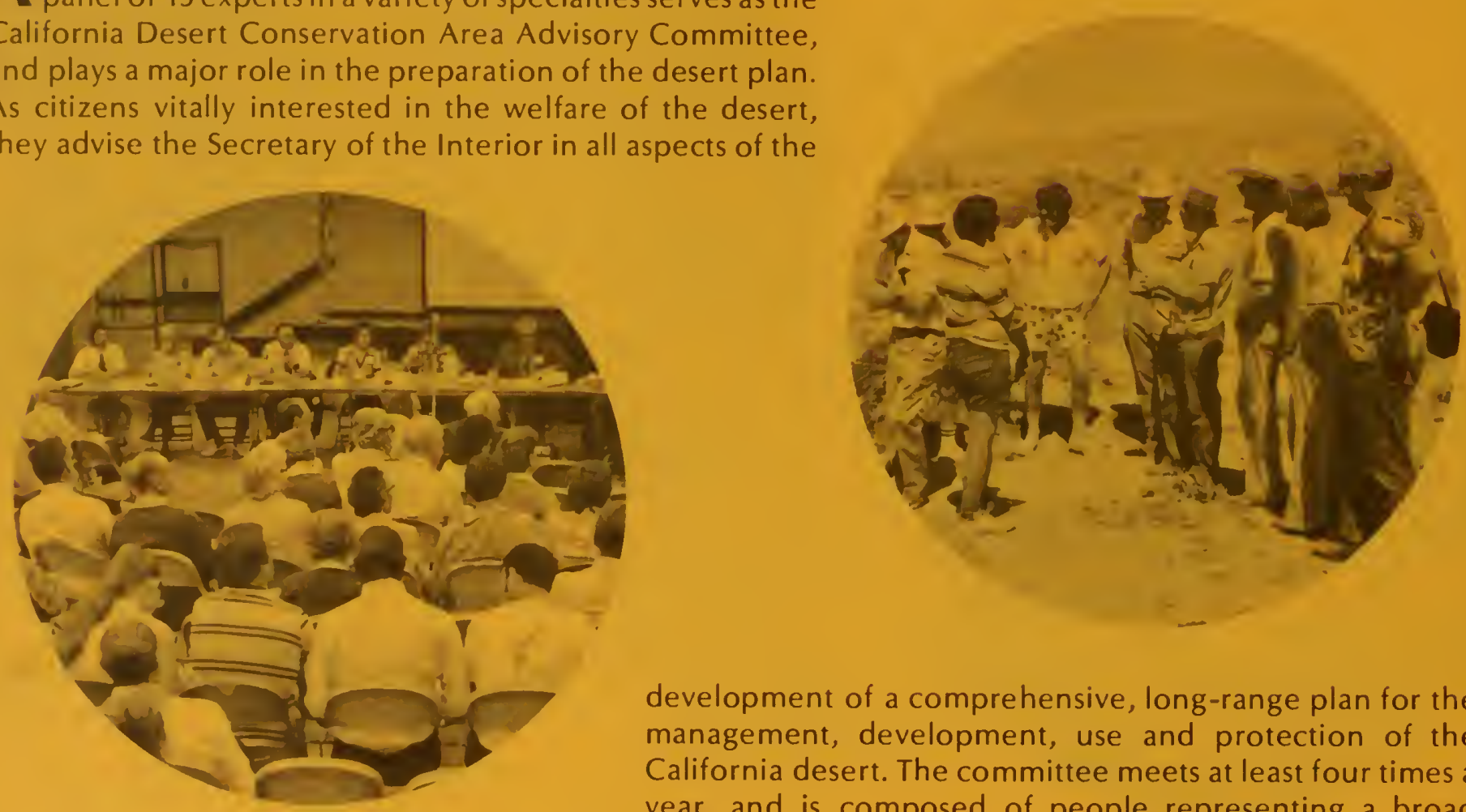

development of a comprehensive, long-range plan for the management, development, use and protection of the California desert. The committee meets at least four times a year, and is composed of people representing a broad spectrum of vocations and avocations.

\section{ADVISORY COMMITTEE}




\section{B. L.M.}

\section{Bureau Planning and Management}

The tight deadline mandated by Congress for completion of the California Desert Plan caused the emphasis to be shifted from unit-by-unit planning to a comprehensive, desert-wide planning approach.

Data collection occupies the first two years of the four-year planning program. Next comes the plan preparation phase, with extensive use of automated data processing. Vast amounts of information must be stored and classified by the Bureau's in-house mini-computer. Socioeconomic aspects of the plan are considered concurrently with the resource elements.

After all the data is collected and a nalyzed, specialists in each resource will outline objectives for individual resources and develop recommendations. The final step will involve planners and resource specialists working together to synthesize these recommendations into a comprehensive "draft" plan.

Meanwhile, during the preparation of the comprehensive long-range plan, the California desert is under an interim management administered by the Bureau of Land Management. Highlighting this plan are the Desert Ranger Program, the Way Stations Program, and a series of specially tailored educational programs.

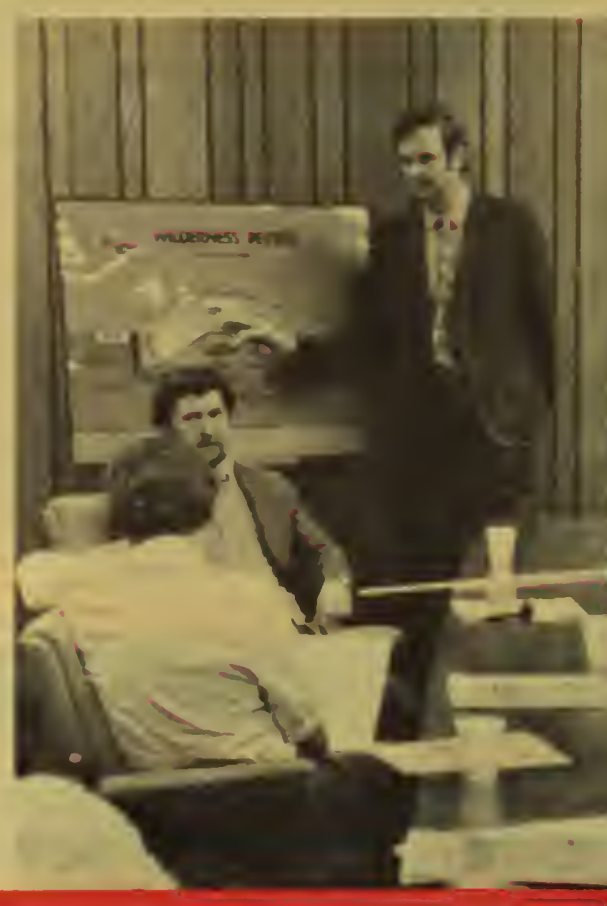


L PROGRESS REPORTS

1977

\begin{tabular}{|c|}
\hline DATA PROCESSING \\
\hline $\begin{array}{c}\text { INTERGOVERNMENTAL } \\
\text { COORDINATION }\end{array}$ \\
\hline POLICY \\
\hline
\end{tabular}

SOCIAL / ECONOMIC PROFILE

ENVIRONMENTAL ASSESSMENT

PLANNING

RESOURCES

AIJVISORY CONMITTEE

PUBLIC PARTICIPATION
ADP / FIELD DATA FROM INVENTORY / DATA ANALYSIS

ANALYZE PLANS \& PROGRAMS OF OTHER AGENCIES

LAWS \& REGULATIONS

SOCIAL/ECONOMIC TREND ANALYSIS

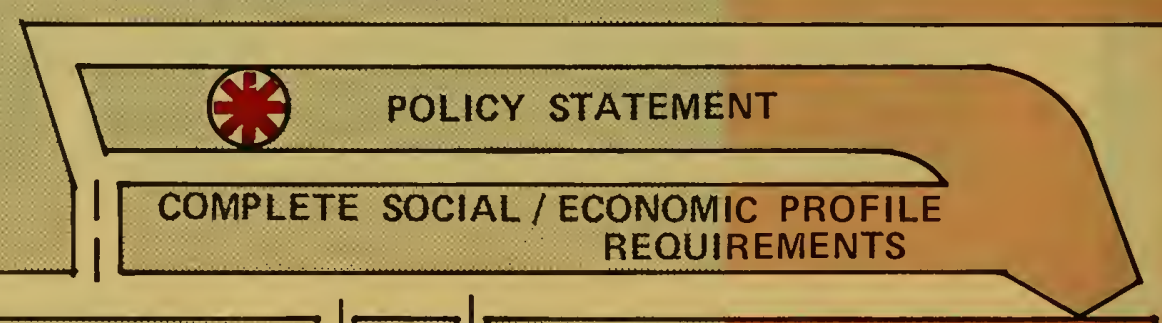

DETERMINE ASSESSMENT REQUIREMENTS \& EIS APPROVAL

PRE - PLANNING PROCESS

- LANDS

- GEOLOGY - ENERGY - MINERALS

- VEgetation - range

- soll - Water - alr

- recreation - scenic quality

- cultural

- WILLDLIFE

- WILDERNESS PROGRAM

REVIEW I RECOMMEND PUBLIC IS ISUE CLARIFICATION S SEMINARS PROGRAM I PARTICIPATION PROGRAM | REVIEW \& AFFIRM PLAN PROCESS

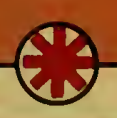

LAN1 DESCRIPTION OF ENVIRONMENT
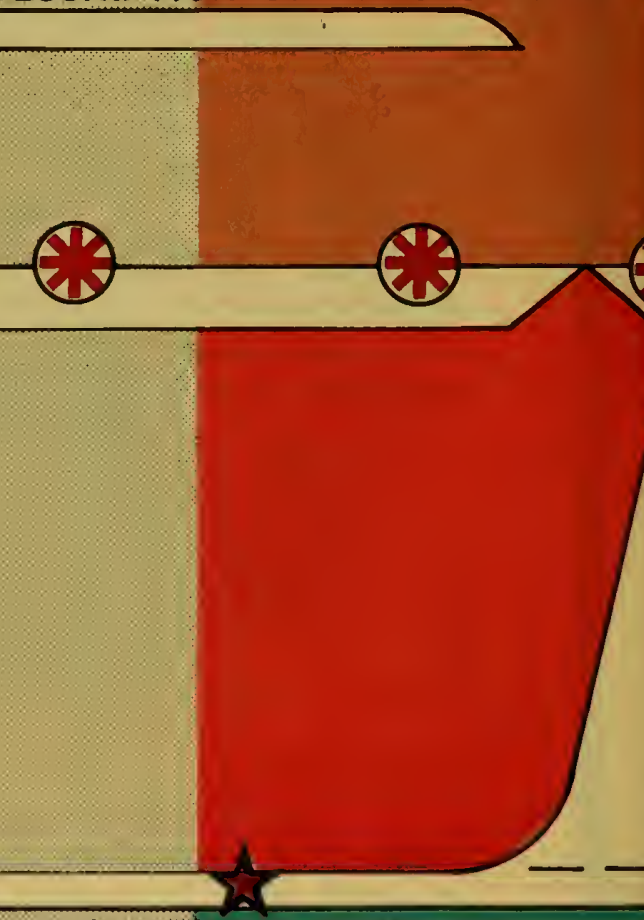

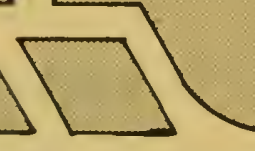

IMPLEMENT

PUBLIC 


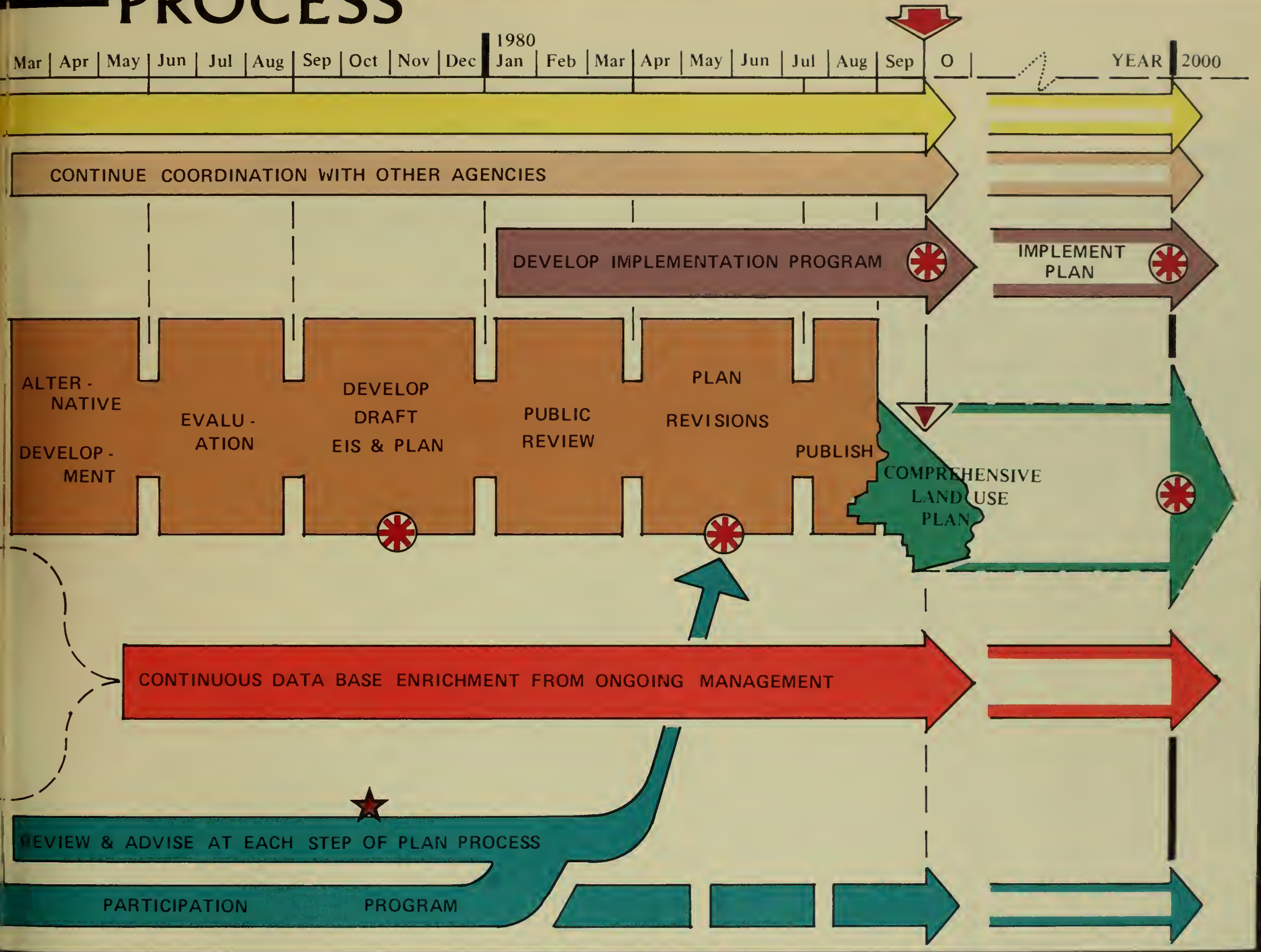




\section{this is your desert,}

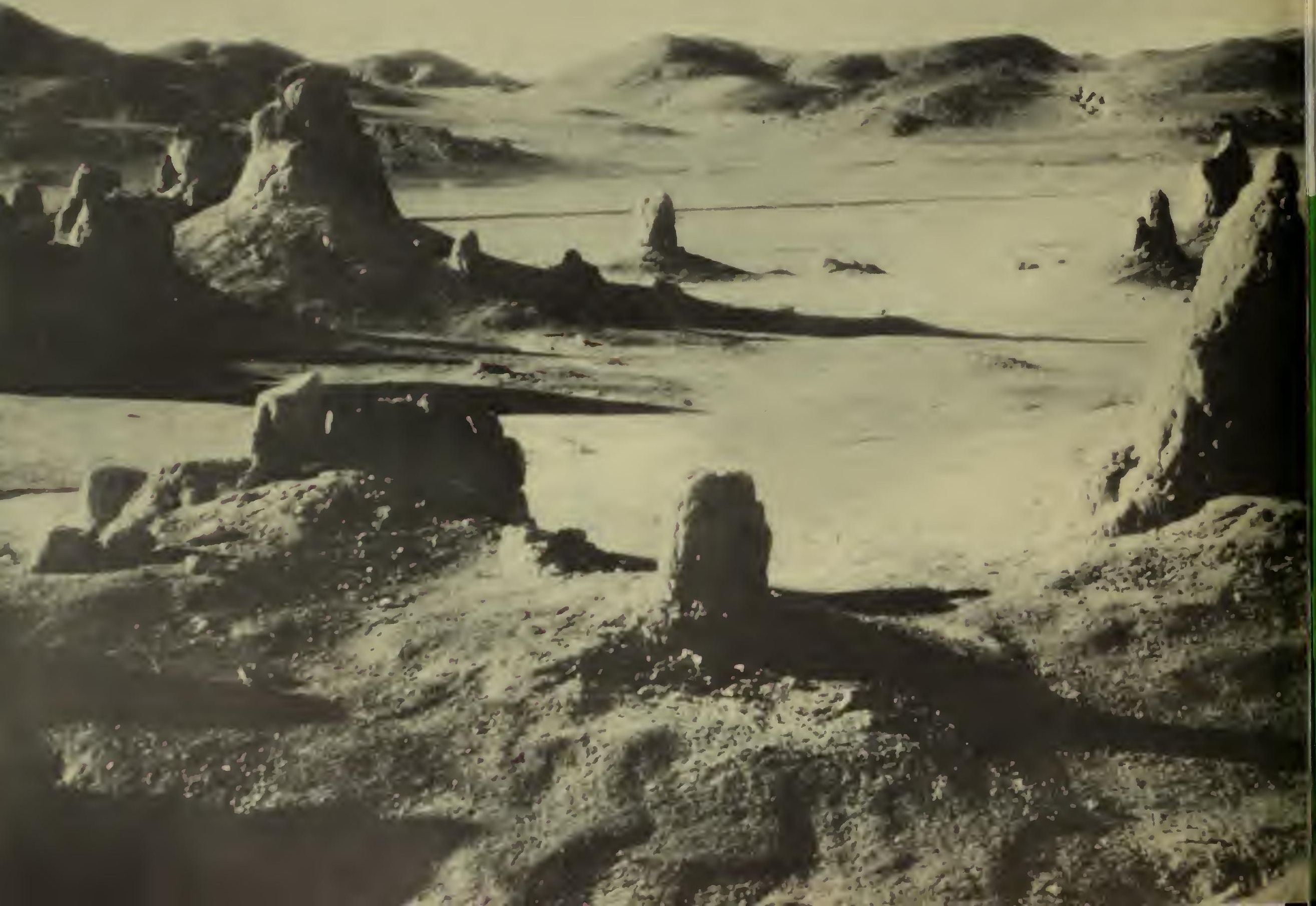




\section{DO YOU CARE}

The real question was asked by an old man resting in the shade of a Palo

Verde tree as he watched his grandchildren's introduction to the desert;

"I wonder how much of this land that we inherited will be left for them to pass on to their grandchildren?"

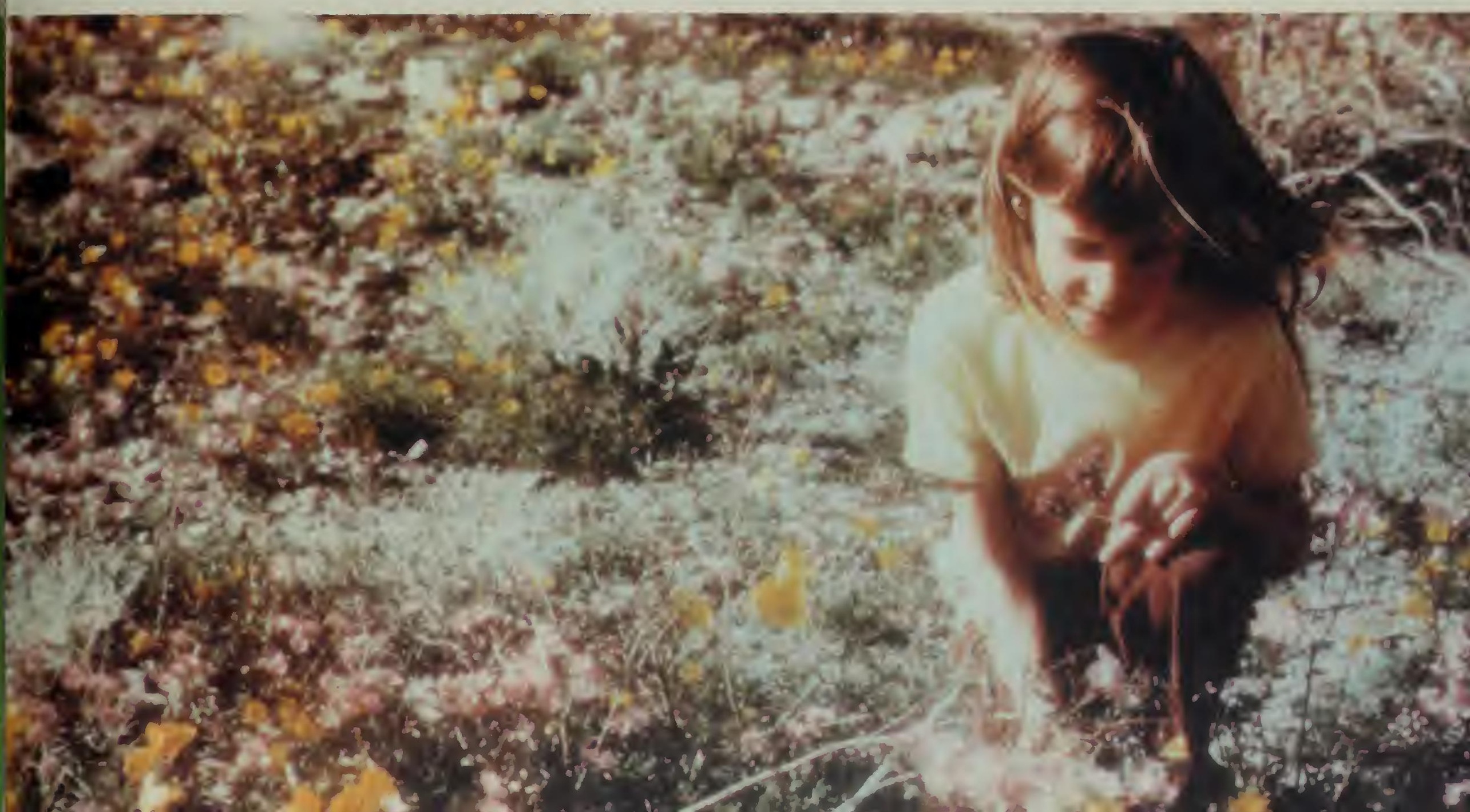




\section{Public}

The Bureau of Land Management has sought public input and involvement in its California Desert Plan from the beginning.

It has been our policy, when important matters like the California Desert Plan are under consideration, to ask the people. .

Do You Care?

Los abenturtar Jnc.

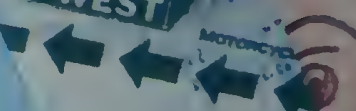
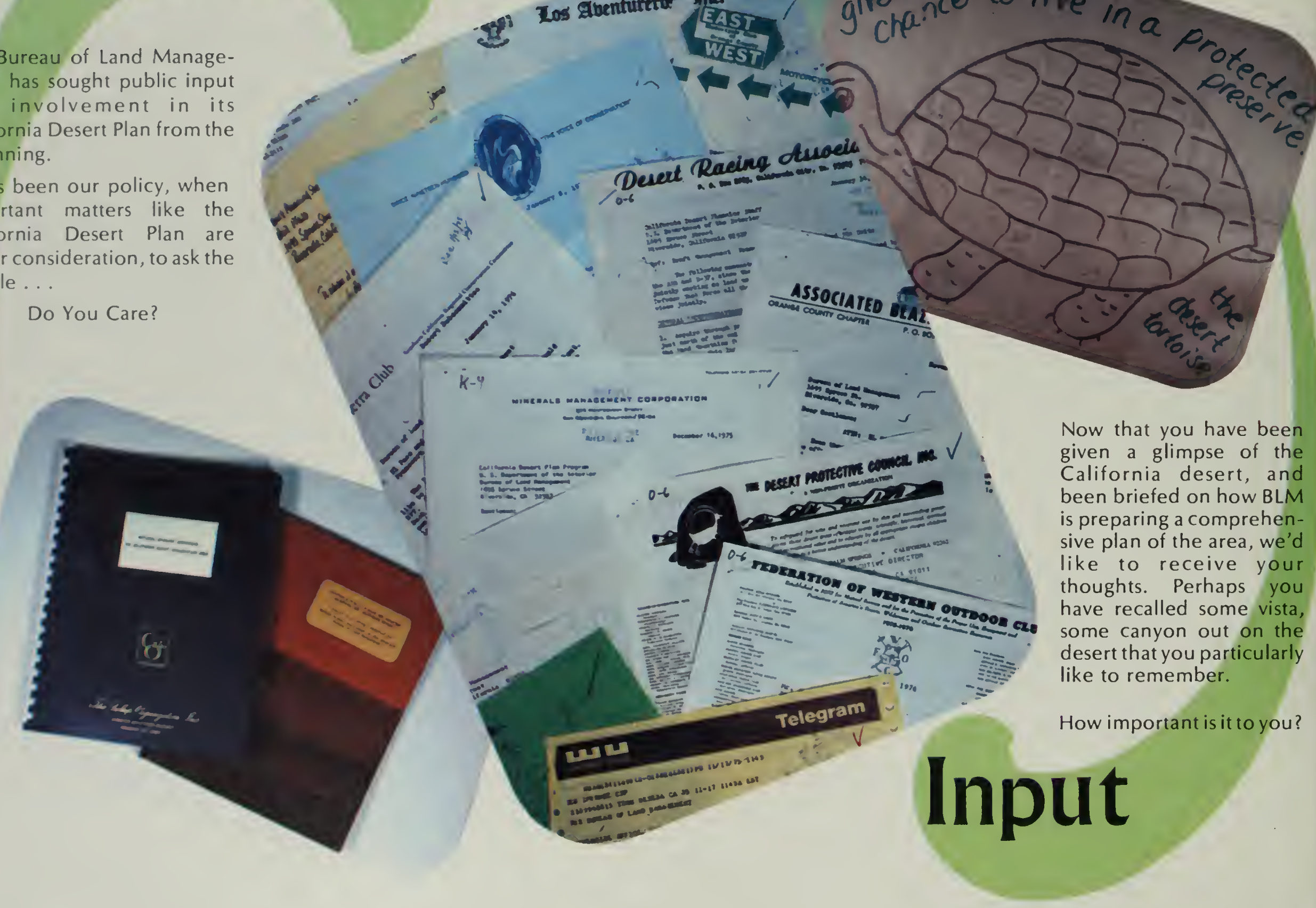

$\therefore$ give mence to live $\ln 0$ 


\section{give us YOUR COMMENTS}

If you do care, and you have a comment or information about the desert, or if you would just like to express your opinion, BLM would like to hear from you.

Public involvement is important to us, but we realize people have many things on their minds besides the management of public lands and resources. That's what this booklet is all about ... to tell you about the California desert and the Plan we are preparing, and to ask you ...

\section{WHAT DO YOU THINK?}

If you have a comment, opinion, question, or otherwise wish to express your thoughts on, or interest in, the California desert, you may do so by using the detachable card.

Thank you.

fold along this line

U.S. DEPARTMENT OF THE INTERIOR BUREAU OF LAND MANAGEMENT 3610 CENTRAL AVE/SUITE 402 RIVERSIDE, CALIFORNIA 92506 OFFICIAL BUSINESS

Penalty for Private Use - $\$ 300$
Postage And Fees Paid U.S. Department Of The Interior INT-415

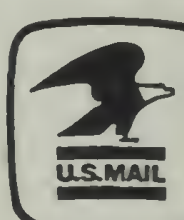

\section{FIRST CLASS MAI}

United States Department of the Interior Bureau of Land Management

CALIFORNIA DESERT PLAN PROGRAM 3610 Central Avenue/Suite 402 Riverside, CA 92506 


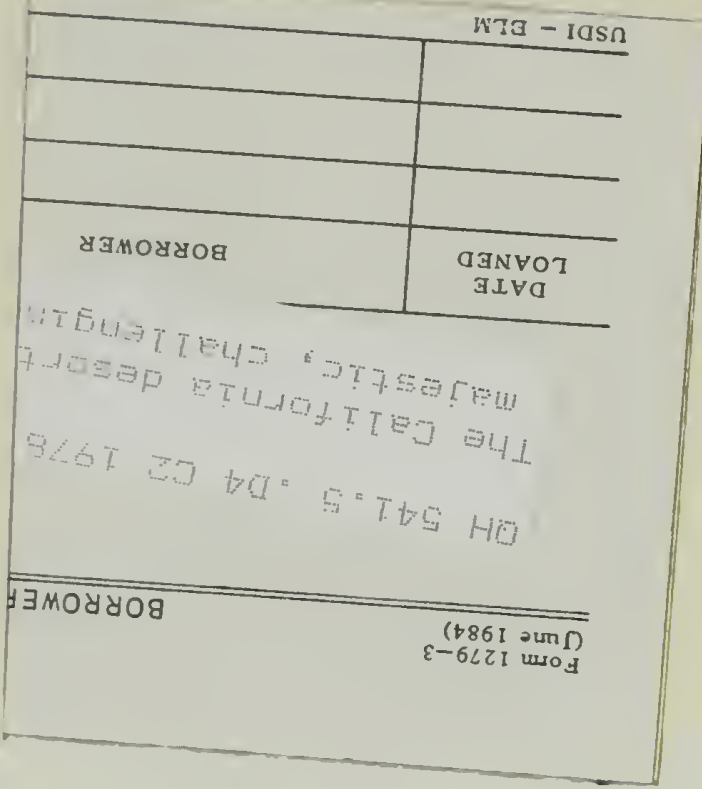

Secretary

Department of the Interior

Cecil Andrus

Director

Bureau of Land Management Frank Gregg

California State Director Bureau of Land Management Ed Hastey

fold along this line

dividuals wishing to contact the Desert Advisory ommittee or the Desert Plan Staff can do so by writing to the llowing:

esert Advisory Committee 510 Central Ave/Suite 402 iverside, CA 92506

Desert Plan Director

Bureau of Land Management

3610 Central Ave/Suite 402

Riverside, CA 92506

ne mailing addresses for other BLM offices are:

\section{ate Director}

ureau of Land Management

deral Office Building

$\begin{array}{ll}\text { dederal Office Building } & 1695 \text { Spruce Street } \\ 00 \text { Cottage Way/Room E-2841 Riverside, CA } 9250\end{array}$

icramento, CA 95825
District Manager

District Manager

Riverside, CA 92507
Bureau of Land Management 800 Truxtun Ave/Room 311 Bakersfield, CA 93301
Desert Plan Director Bureau of Land Management Neil Pfulb 


\section{CALIFORNIA DESERT CONSERVATION AREA}

Sec. 601. (a) The Congress finds that -

(1) the California desert contains historical, scenic, archaeological, environmental, biological, cultural, scientific, educational, recreational, and economic resources that are uniquely located adjacent to an area of large population;

(2) the California desert environment is a total ecosystem that is extremely fragile, easily scarred, and slowly healed;

(3) the California desert environment and its resources, including certain rare and endangered species of wildlife, plants, and fishes, and numerous archaeological and historic sites, are seriously threatened by air pollution, inadequate Federal management authority, and pressures of increased use, particularly recreational use, which are certain to intensify because of the rapidly growing population of southern California;

(4) the use of all California desert resources can and should be provided for in a multiple use and sustained yield management plan to conserve these resources for future generations, and to provide present and future use and enjoyment, particularly outdoor recreation uses, including the use, where appropriate, of off-road recreational vehicles;

(5) the Secretary has initiated a comprehensive planning process and established an interim management program for the public lands in the California desert; and,

(6) to insure further study of the relationship of man and the California desert environment, preserve the unique and irreplaceable resources, including archaeological values, and conserve the use of the economic resources of the California desert, the public must be provided more opportunity to participate in such planning and management, and additional management authority must be provided to the Secretary to facilitate effective implementation of such planning and management.

(b) It is the purpose of this section to provide tor the immediate and future protection and administration of the public lands in the California desert within the framework of a program of multiple use and sustained yield, and the maintenance of environmental quality.

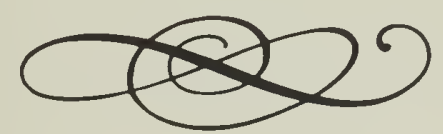

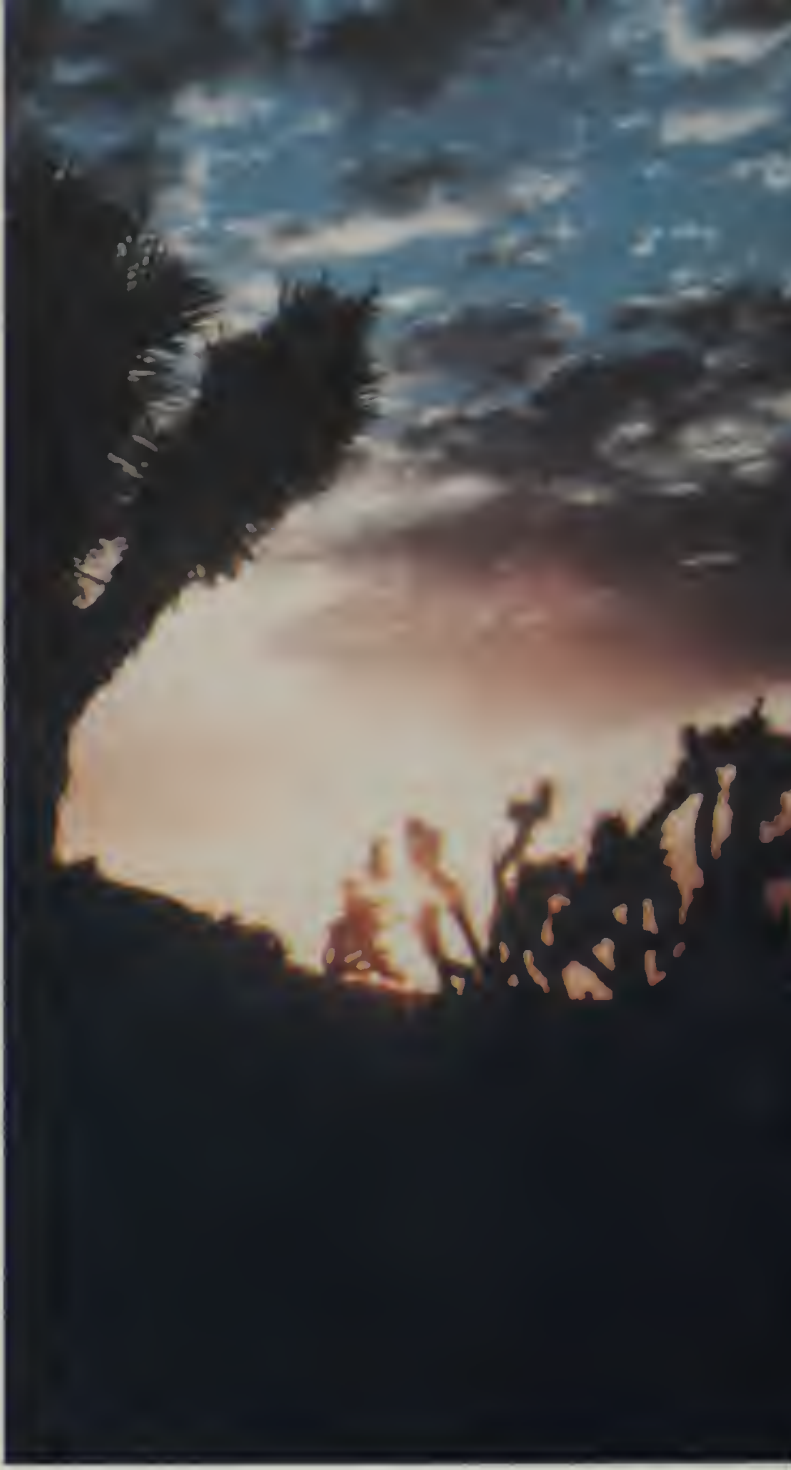

United States Department of the Interior:

As the Nation's principal conservation agency, the Departr Interior has responsibility for most of our nationally owned 8 and natural resources. This includes fostering the wisest use and water resources, protecting our fish and wildlife, pre environmental and cultural values of our national parks a places, and providing for the enjoyment of life throug recreation. The Department assesses our energy and minera and works to assure that their development is in the best in! our people. The Department of the Interior also ha responsibility for American Indian reservation communit people who live in Island Territories under the Un administration. 


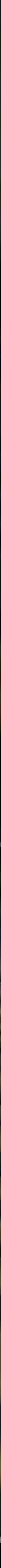

